\title{
Sirtuins, a promising target in slowing down the ageing process
}

\author{
Wioleta Grabowska $\cdot$ Ewa Sikora $\cdot$ Anna Bielak-Zmijewska 10
}

Received: 27 January 2017/ Accepted: 21 February 2017/Published online: 3 March 2017

(C) The Author(s) 2017. This article is published with open access at Springerlink.com

\begin{abstract}
Ageing is a plastic process and can be successfully modulated by some biomedical approaches or pharmaceutics. In this manner it is possible to delay or even prevent some age-related pathologies. There are some defined interventions, which give promising results in animal models or even in human studies, resulting in lifespan elongation or healthspan improvement. One of the most promising targets for anti-ageing approaches are proteins belonging to the sirtuin family. Sirtuins were originally discovered as transcription repressors in yeast, however, nowadays they are known to occur in bacteria and eukaryotes (including mammals). In humans the family consists of seven members (SIRT1-7) that possess either mono-ADP ribosyltransferase or deacetylase activity. It is believed that sirtuins play key role during cell response to a variety of stresses, such as oxidative or genotoxic stress and are crucial for cell metabolism. Although some data put in question direct involvement of sirtuins in extending
\end{abstract}

W. Grabowska · E. Sikora · A. Bielak-Zmijewska ( $\square)$ Laboratory of Molecular Bases of Aging, Department of Biochemistry, Nencki Institute of Experimental Biology of Polish Academy of Sciences, Pasteur Str. 3, 02-093 Warsaw, Poland e-mail: w.grabowska@nencki.gov.pl

E. Sikora

e-mail: e.sikora@nencki.gov.pl

A. Bielak-Zmijewska

e-mail: a.bielak@nencki.gov.pl human lifespan, it was documented that proper lifestyle including physical activity and diet can influence healthspan via increasing the level of sirtuins. The search for an activator of sirtuins is one of the most extensive and robust topic of research. Some hopes are put on natural compounds, including curcumin. In this review we summarize the involvement and usefulness of sirtuins in anti-ageing interventions and discuss the potential role of curcumin in sirtuins regulation.

Keywords Sirtuins $\cdot$ Ageing $\cdot$ Senescence . Curcumin

\section{Introduction}

In the year 1979 a paper announcing discovery of mating-type regulator 1 (MAR1) in Saccharomyces cerevisiae was published (Klar et al. 1979). Lack of this protein resulted in the inhibition of silencing of HM loci, which control the mating type and sterility in yeast. Three more proteins with similar function were discovered later in 1979 and the nomenclature was unified thus creating a family of Sir (silent information regulator) proteins (Michan and Sinclair 2007). Shortly, it was shown that sirtuins are evolutionarily conserved from bacteria to humans (Vaquero 2009). We now know a number of processes sirtuins are involved in and we still discover their new functions. In bacteria phosphoribosyltransferases cobT and cobB 
catalyze the synthesis of the cobalamin biosynthetic intermediate (which transfers a ribose-phosphate moiety from nicotinic acid mononucleotide (NaMN) to dimethyl benzimidazole 2) and in archaea Sir-2-Af1 and Sir2-Af2 participate in transcription regulation (Tsang and Escalante-Semerena 1998). While in prokaryotes there are usually one or two sirtuin genes, eukaryotes can have multiple sirtuin genes. In yeast, in addition to the chief representative, Sir2, there are four more homologous proteins (Michan and Sinclair 2007). In mammals there are seven enzymes belonging to the sirtuin family, among which SIRT1 (silent information regulator $\mathrm{T} 1$ ) has the highest sequence homology to Sir2 in yeast and is the best studied family member. Modulation of sirtuin activity in mammals can regulate many processes such as gene expression, cell metabolism, apoptosis, DNA repair, cell cycle, development, immune response and neuroprotection (Michan and Sinclair 2007).

A significant rise in the interest in sirtuins occurred in 1999 when it was reported that Sir2 overexpression can extend yeast lifespan by as much as $70 \%$ (Kaeberlein et al. 1999). The anti-ageing action of sirtuins appears to be conserved from yeast to mammals, however the complexity of their function increases with the complexity of the organism. In yeast, the positive effect of sirtuins activity can be attributed to the increase in genomic stability in two ways. There are from 100 to 200 copies of ribosomal DNA (rDNA) in each yeast cell, however, only half of them are transcriptionally active, the rest remains silent (Sinclair and Guarente 1997). Together with other proteins, Sir2 participates in silencing of these regions. Such silencing prevents recombination between rDNA repeats and formation and accumulation of extrachromosomal rDNA circles (ERCs), which are a leading cause of yeast ageing (Sinclair and Guarente 1997). Mutations in Sir2 gene lead to accelerated accumulation of toxic ERCs, whereas Sir2 overexpression extends $S$. cerevisiae lifespan by silencing HML/R loci and inhibiting ERCs formation (Kaeberlein et al. 1999). Furthermore, along with yeast ageing Sir2 dissociates from HM loci, which results in termination of HM silencing and in sterility, which is a sign of yeast senescence (Sinclair and Guarente 1997). Therefore, changes in the localization of Sir2 result in epigenetic alterations that favor ageing. It was shown that Sir2 is indispensable for mediating positive effects of calorie restriction in yeast (Lin et al. 2000). It was also observed that the level of Sir2 increases during calorie restriction in $S$. cerevisiae (Bordone and Guarente 2005).

Further research revealed that sirtuin overexpression leads to lifespan extension also in other model organisms such as Caenorhabditis elegans and Drosophila melanogaster. In mammals sirtuins regulate numerous signaling pathways (not only those directly involved in ageing and senescence). This complex influence of sirtuins on mammalian ageing is discussed in this review.

Function, structure and localization

In the early 1990s Braunstein et al. showed that regions silenced by Sir2 were characterized by reduced histone acetylation at the $\varepsilon$-amino group of $\mathrm{N}$-terminal lysine residues (Braunstein et al. 1993). Some authors also observed that Sir2 overexpression in yeast led to global hypoacetylation. Soon it was discovered that the main activity of sirtuins is deacetylation of lysine residues. This is a two-step reaction-firstly sirtuins cleave nicotinamide adenine dinucleotide (NAD) to nicotinamide (NAM) and, subsequently, an acetyl/acyl group is transferred from the substrate to the ADP-ribose moiety of NAD; this results in the formation of $2^{\prime}-O$-acetyl-ADP-ribose and a deacetylated substrate (Tanner et al. 2000).

Sirtuins belong to class III histone deacetylases (HDAC). A distinguishing feature of this class is that the catalytic activity of the enzymes depends on $\mathrm{NAD}+$ and is regulated by dynamic changes in $\mathrm{NAD}+$ level and the NAD+/NADH ratio. Such requirement for NAD+ as a co-substrate suggests that sirtuins might have evolved as sensors of energy and redox status in the cell (Michan and Sinclair 2007). There are two pathways of NAD+ biosynthesis-de novo production and the so called salvage pathway. In the salvage pathway NAM is converted to nicotinamide mononucleotide (NMN) by nicotinamide phosphoribosyltransferase (NAMPT), a limiting enzyme for the whole pathway. Subsequently, $\mathrm{NMN}$ is converted to NAD+ by NMN/NaMN adenylyltransferase (NMNAT) (Chung et al. 2010). The level of NAMPT can influence sirtuin activity. NAD+ synthesis is coupled with the circadian/daily cycle due to the fact that NAMPT is regulated by a complex consisting of CLOCK (circadian locomotor output cycles kaput) and BMAL1 (brain and muscle aryl 
hydrocarbon receptor nuclear translocator-like 1) (Nakagawa and Guarente 2011). Unlike NAMPT, PARP1 activation by DNA damage results in a decrease in the NAD+ level (PARP1 uses NAD+ as a cofactor) and inhibition of sirtuin activity (Zhang 2003). NAM (another product of the reaction catalyzed by sirtuins) is a non-competitive inhibitor of sirtuin activity (Chung et al. 2010).

Sirtuins deacetylate not only histones but also some transcription factors and cytoplasmic proteins. Recent research shed some new light on sirtuins as it was shown that in addition to deacetylation they can remove some other moieties as well. For example, SIRT6 catalytic activity increases with the size of the aliphatic tail it removes, so that palmitoyl, myristoyl or butyryl are favored over acetyl moiety (Gertler and Cohen 2013). Therefore, it is now considered that sirtuins are not deacetylases but a more general term is proposed-deacylases (Jiang et al. 2013). Acetylation is a post-translational protein modification which can affect, among others, catalytic activity, stability and ability to bind to other proteins or chromatin (which is especially important in the case of histones).

In human we can distinguish seven sirtuins (SIRT17). Their catalytic domain consists of 275 amino acids and is common to all family members. Activity of some sirtuins is not limited only to protein deacetylation. ADP-ribosylation is the main activity for SIRT4, which lacks deacetylase activity, and is also characteristic for SIRT6 (Morris 2013). Moreover, SIRT5 can demalonylate and desuccinylate proteins (Du et al. 2011). SIRT1, SIRT6 and SIRT7 localize mainly in the nucleus. SIRT7 has been found to be a part of the RNA Pol I transcription machinery and is expressed in the nucleoli where it can bind to histones and positively regulate rDNA transcription (Ford et al. 2006). SIRT2 can be found mostly in the cytoplasm where its main substrate is $\alpha$-tubulin ( $\mathrm{Li}$ et al. 2007). Still, a fraction of SIRT2 can translocate to the nucleus where it takes part in regulation of the cell cycle (Dryden et al. 2003). SIRT3, SIRT4 and SIRT5 have been termed mitochondrial sirtuins. SIRT3 is cleaved to its active form by the mitochondrial matrix processing peptidase (Schwer et al. 2002). Full-length SIRT3 resides in the nucleus, however, in response to stress (such as DNA damage) it translocates to the mitochondria (Scher et al. 2007).
Anti-ageing potential of sirtuins: in vivo and in vitro studies

Ageing is associated with numerous changes at the organismal, tissue as well as cellular level. With age, senescent cells accumulate in many tissues impairing their proper functioning. Senescent cells have a strong impact on surrounding cells. They modify the microenvironment by secreting certain cytokines, chemokines and mediators of inflammation. Such secretory phenotype is one of the causes of a low grade inflammation observed in old individuals and can induce senescence in neighboring cells as well as support tumor progression. Senescent cells, apart from the secretory phenotype, possess a set of features such as increased: level of cell cycle inhibitors, activity of senescence associated $\beta$-galactosidase, granularity and DNA damage. The elevation of DNA damage with age is the result of impaired efficiency of DNA repair systems. It is believed that DNA damage is the main cause of cellular senescence. It concerns both replicative (critically short telomeres are considered as DNA double strand breaks) and stress (oxidative, genotoxic) induced senescence. DNA damage is associated with normal functioning of cells and efficient repair systems are sufficient to protect cells from its accumulation. However, age-related decrease in the ability to repair DNA, causes increased damage accumulation and, in consequence, cell senescence. Sirtuins are indispensable for DNA repair, controlling inflammation and antioxidative defense which makes them good anti-senescence/anti-ageing targets.

Calorie restriction (CR) is so far the only effective way to extend lifespan without genetic or pharmacological intervention (more information about $\mathrm{CR}$ in the chapter concerning Intervention). The effects of calorie restriction (besides lifespan extension) are manifested by physiological and behavioral changes such as reduced size, decreased level of growth factors, glucose, triglycerides and increase in the locomotor and foraging activity (McCarter et al. 1997; Weed et al. 1997). The level of almost all sirtuins, except SIRT4, increases as an effect of calorie restriction (Watroba and Szukiewicz 2016). Therefore, it is believed that sirtuins mediate beneficial effects elicited by such diet. However, sirtuin antiageing activity is not limited to mediating the $\mathrm{CR}$ effects. Plethora of in vivo and in vitro studies show 
importance of these enzymes for reaching a lifespan characteristic for a particular species.

\section{SIRT1}

SIRT1 is the best studied in the family. It plays an important role during fetal development. In the case of mouse zygotes lacking both copies of SIRT1 gene only half of the expected individuals are born of which only $20 \%$ reach maturity. Such mice are sterile, smaller than normal individuals, develop more slowly and experience abnormalities in morphogenesis of the eye and heart. The latter likely contributes to the neonatal lethality of SIRT1 depleted mice (McBurney et al. 2003; Cheng et al. 2003). Additionally, among heterozygous embryos cases of anencephaly were reported.

The level of SIRT1 decreases in the liver with age, probably due to lower NAD+ availability (Braidy et al. 2011) while a simultaneous increase in accumulation of DNA damage occurs. Age-dependent decrease in the level of SIRT1 was observed also in the arteries, suggesting its involvement in the ageing of the cardiovascular system (Bai et al. 2014). Decrease in SIRT1, caused by accelerated senescence of cord blood endothelial cells, was also a cause of early vascular dysfunction observed in low birth weight preterm infants (Vassallo et al. 2014). SIRT1 deficiency promoted expression of genes characteristic for ageing (Hwang et al. 2013).

Mice with an extra copy of SIRT1 gene are characterized by a lower level of DNA damage and of p16, which are the hallmarks of ageing (Herranz et al. 2010). It was shown, that tissue-specific overexpression of SIRT1 in cardiac muscle cells diminished the area affected by myocardial infarction and facilitated recovery (Hsu et al. 2010). It was also shown that some single-nucleotide polymorphisms (SNP) in the SIRT1 gene could affect SIRT1 activity and correlate with BMI and a tendency to diet-induced obesity (Clark et al. 2012). However, no correlation between changes in SIRT1 activity (caused by SNP) and lifespan extension was found (Flachsbart et al. 2006).

SIRT1 was shown to delay replicative senescence of normal human umbilical cord fibroblasts and regulate both replicative and premature senescence in stem cells and differentiated cells exposed to oxidative stress (Bellizzi et al. 2005; Brown et al.
2013). Activation of the salvage pathway in vascular smooth muscle cells (VSMC) results in an increase in the replicative lifespan of these cells due to SIRT1 activation (Canto et al. 2009). Moreover, it was demonstrated that inhibition of NAMPT led to premature replicative senescence, while its overexpression delayed it (Yang and Sauve 2006). The level of SIRT1 decreases in tissues, in which cells proliferate during the organismal lifespan or during long term in vitro culture, as we have recently also shown for VSMC (Bielak-Zmijewska et al. 2014), but not in immortalized cells (Sasaki et al. 2006). In $\mathrm{H}_{2} \mathrm{O}_{2^{-}}$or genotoxic stress-induced cellular senescence PARP1 becomes activated, which results in depletion of NAD+ resources and leads to a decrease in SIRT1 activity (Furukawa et al. 2007). There are data suggesting that SIRT1 can be involved in decisionmaking over cellular senescence or apoptosis. In the $3^{\prime}$ UTR region of the SIRT1 transcript there is a HuR binding site. HuR is an RNA-binding protein, which can stabilize a transcript when bound. The level of HuR decreases dramatically during senescence (which can also be the cause of the decrease in SIRT1 level observed with ageing). In response to oxidative DNA damage HuR is phosphorylated by Chk2, which leads to its dissociation from SIRT1 mRNA. As a result, there is a decrease in the level of SIRT1 and cells become more prone to apoptosis (Abdelmohsen et al. 2007). It is possible that the described phenomenon is one of the mechanisms responsible for sustaining the balance between DNA repair, senescence and apoptosis. High level of DNA damage can activate Chk2, which leads to a decrease in SIRT1 level and moves the balance towards apoptosis (Bosch-Presegué and Vaquero 2011).

Pleiotropic activity of SIRT1 makes it an important marker of cellular senescence as well as some diseases such as cardiovascular and neurodegenerative diseases, diabetes or cancer (Nakagawa and Guarente 2011).

\section{SIRT2}

Expression of SIRT2 decreases in fat tissue of obese people (Krishnan et al. 2012). On the other hand, the level of SIRT2 increases in white fat tissue and kidneys of mice subjected to calorie restriction (Wang et al. 2007). Recent studies suggest that SIRT2 can serve as a cellular senescence marker. It was shown that the level of SIRT2 increased in senescent cells 
(regardless of whether the inducing factor was stress, oncogene or exhaustion of replicative potential) but not in quiescent cells or in cells that entered apoptosis (Anwar et al. 2016). At the same time, the authors excluded SIRT2 as an indispensable factor in senescence induction. This suggests that the increase in the level of SIRT2 is rather the effect of the changes occurring in cells during senescence, than the cause of senescence.

\section{SIRT3}

SIRT3 is the only sirtuin for which evidence exists that it can influence longevity in humans. It was shown that a certain polymorphism in SIRT3 gene can be found more often in long-lived people (Bellizzi et al. 2007, 2005). A variable number of tandem repeats in intron five enhancer region can affect activity of this enhancer. People carrying the allele with the least active enhancer were less likely to survive to an old age. Such variant was practically absent in men over 90 years old living in Italy (Bellizzi et al. 2005). However, studies of other larger populations did not confirm those findings, suggesting that SIRT3 influence on longevity is negligible or even nonexistent (Lescai et al. 2009; Rose et al. 2003).

Mice lacking SIRT3 are characterized by decreased oxygen consumption and simultaneous increase in reactive oxygen species (ROS) production as well as higher oxidative stress in muscle (Jing et al. 2011). Such observations were confirmed in cell culturecells lacking SIRT3 had increased ROS level, which could induce DNA damage and activate HIF1 $\alpha$ (Finley et al. 2011; Bell et al. 2011). SIRT3 activates enzymes, that play key roles during $\mathrm{CR}$, such as 3-hydroxy-3methyl-glutaryl-CoA synthase responsible for ketone formation (Shimazu et al. 2010) and long chain acylCoA dehydrogenase responsible for long-chain fatty acid oxidation (Hirschey et al. 2010).

\section{SIRT1, SIRT2, SIRT3}

Recent data have shown that the ageing protection mechanism involving sirtuins is quite universal and concerns also germ cells. The ageing of oocytes reduces the quality of metaphase II oocytes, which undergo time-dependent deterioration following ovulation. In mouse oocytes aged in vivo or in vitro the expression of SIRT1, SIRT2 and SIRT3 was dramatically reduced. On the other hand, it has been shown that prolonged expression of SIRT1, SIRT2 and SIRT3 reduced mouse oocyte ageing both in vitro and in vivo (Zhang et al. 2016a), which suggests a potential protective role of these enzymes against postovulatory ageing. SIRT1 and SIRT3 are the sensors and guardians of the redox state in oocytes, granulosa cells and early embryos and therefore play a crucial role in female fertility especially when oocyte ageing is concerned (reviewed in Tatone et al. 2015).

The age-dependent changes in sirtuin level could be used as a diagnostic tool. Serum sirtuins are considered as a novel noninvasive protein marker of frailty (Kumar et al. 2014a). Frailty is a complex clinical state described as a characteristic set of features among older patients. Diagnosis of frailty is often difficult because of subtle and subjective clinical features, especially at the early stage of the syndrome. To the features of frailty belong: sarcopenia, cognitive decline, abnormal functioning of immune and neuroendocrine systems, poor energy regulation (Clegg et al. 2013). Currently, there is no defined treatment for frailty. It will be useful to find a set of biochemical abnormalities associated with frailty for better and earlier diagnosis. Sirtuins circulating in serum could be potential markers of frailty. As suggested by analysis of people diagnosed as frail in comparison to non frail individuals, lower levels of SIRT1 and SIRT3 were associated with frailty.

\section{SIRT6}

The first evidence that sirtuins can be involved in regulation of mammalian ageing came from mice lacking SIRT6. It appears that among sirtuins, SIRT6 depletion exhibits the most severe phenotype as it seems to be indispensable for reaching a normal lifespan. Three weeks after birth such mice exhibit symptoms of degeneration and premature ageing such as sudden decrease in subcutaneous fat, lordokyphosis, colitis, severe lymphopenia, osteopenia, which all together result in death in about the fourth week of life. SIRT6 $^{-1-}$ mice are also smaller than wild type individuals. Furthermore, severe metabolic abnormalities were observed i.e. low level of IGF-1 and glucose (Mostoslavsky et al. 2006). Later, it was shown that the main reason of premature death was hypoglycemia caused by increased glucose uptake (due to higher expression of GLUT1 and GLUT 4 transporters) (Xiao 
et al. 2010; Zhong et al. 2010). On the other hand, Kanfi et al. demonstrated that overexpression of SIRT6 could also reduce the activity of the IGF-1 pathway. They observed a decrease in the level of IGF-1, the level of IGF-binding protein was increased, and the phosphorylation status of the main components of the IGF-1 signaling pathway was altered. Such changes facilitated glucose tolerance and reduced fat accumulation, which resulted in lifespan extension of male mice (Kanfi et al. 2012).

Mouse embryonal fibroblasts (MEF) and embryonal stem (ES) cells devoid of SIRT6 are characterized by decreased proliferation rate and increased genomic instability as well as sensitivity to stress manifested by chromosome fragmentation, detached centromeres, chromosome loss and translocations. SIRT6 level decreases in human fibroblasts during senescence (Sharma et al. 2013) but also in vascular smooth muscle cells and endothelial cells isolated from human aorta as we have recently demonstrated (Grabowska et al. 2016).

\section{$\operatorname{SIRT7}$}

SIRT7 ${ }^{-1-}$ mice age prematurely and are characterized by a progeroid phenotype and lethal heart hypertrophy (Vakhrusheva et al. 2008). During replicative senescence SIRT7 translocates from nucleoli to chromatin and cytoplasm (Grob et al. 2009), which can result in reduced rDNA transcription. Localization, activity, functions and role in senescence/ageing of all sirtuins are summarized in Table 1.

The mechanisms of senescence modulation by sirtuins

The data presented above support the notion that sirtuins play an important role during ageing. It is best evidenced by a widely observed decrease in the level of almost all sirtuins in senescent cells. The mechanism of their action is very complex and not entirely understood yet.

During cellular senescence changes in chromatin condensation and gene expression occur. Such changes in chromatin structure can influence genome stability, making DNA more susceptible to damage, which is considered the main cause of senescence. Sirtuins play a vital role in sustaining genome integrity. They take part in maintaining normal chromatin condensation state, in DNA damage response and repair, modulate oxidative stress and energy metabolism. Let us take a closer look at the role of each sirtuin in these processes.

\section{Influence on chromatin condensation and gene expression}

Among cells isolated from mice lacking both copies of SIRT1 gene, almost $40 \%$ have impaired chromosome structure including breaks or relaxed/disorganized chromatin (in comparison to 5\% in normal individuals) (Wang et al. 2008). It is suggested that such abnormalities can be the effect of an increase in the acetylation of $\mathrm{H} 3 \mathrm{~K} 9$, caused by lack of SIRT1. Acetylation of $\mathrm{H} 3 \mathrm{~K} 9$ prevents its trimethylation and impairs binding of heterochromatin protein 1 alpha (HP1 $\alpha$ ) responsible for keeping chromatin in a closed state (Wang et al. 2008). SIRT1 (and also other sirtuins), through histone deacetylation, takes part in formation of the constitutive as well as facultative heterochromatin. The removal of acyl groups from histones enhances their affinity to DNA and impedes the access of transcription factors to DNA resulting in silencing of genes neighboring the deacetylated histones (Michan and Sinclair 2007). SIRT1 preferentially deacetylates H4K16, H3K9, H3K56 and H1K26 (Poulose and Raju 2015) and also H1K9 and H3K14 during heterochromatin formation (Michan and Sinclair 2007). It was shown that SIRT1 can be found in telomere and pericentromere regions. Oxidative stress inhibits this interaction, which results in altered gene expression (Oberdoerffer et al. 2008; Palacios et al. 2010). Moreover, SIRT1 deficient mice lack pericentromeric heterochromatin foci (Bosch-Presegué et al. 2011), which suggest its involvement in formation of constitutive heterochromatin.

SIRT1 can influence chromatin condensation not only by deacetylating histones, but also by regulating histone expression and modulating the level and activity of some histone modifying enzymes (Vaquero et al. 2007). SIRT1 can inhibit Suv39h1 methyltransferase degradation by inhibiting polyubiquitination of this methyltransferase by MDM2. Moreover, deacetylation of K266 in the catalytic domain of Suv39h1 activates it (Vaquero et al. 2007). Therefore, SIRT1 promotes H3K9 trimethylation not only by deacetylation but also through cooperation with Suv39h1 (Bosch-Presegué and Vaquero 2011). Under oxidative 


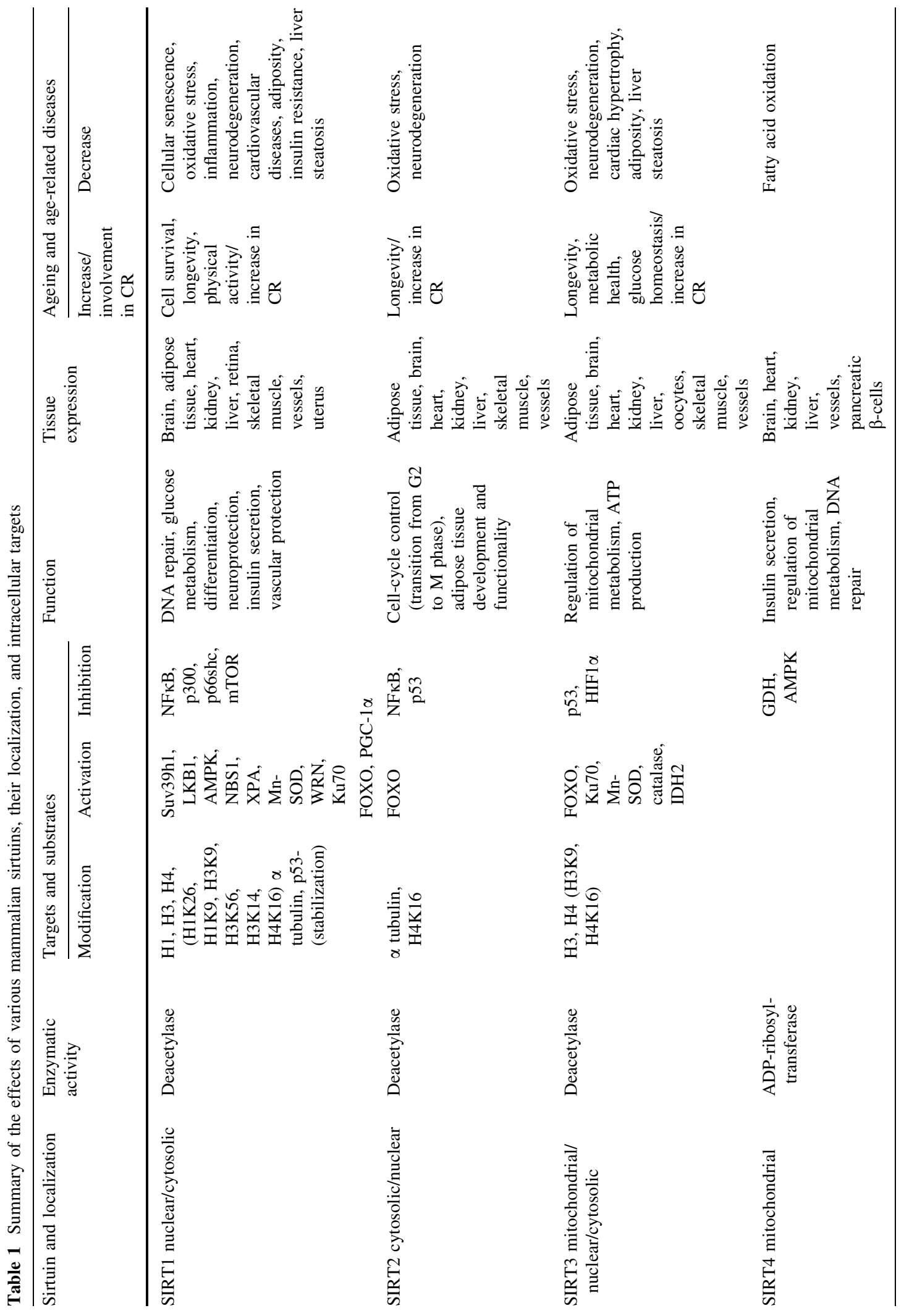




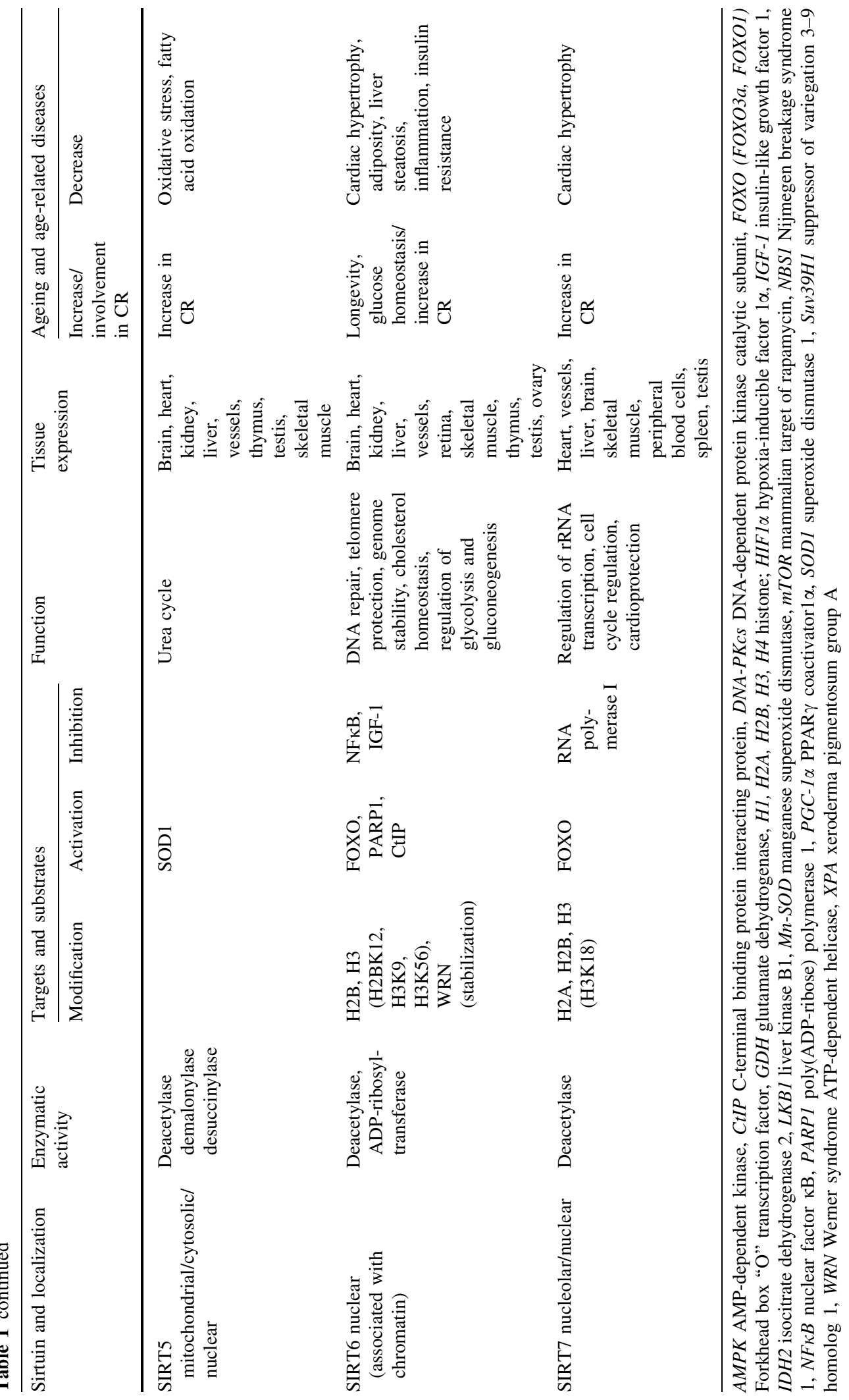


stress, SIRT1 along with Suv39h1 and nucleomethylin initiate formation of facultative heterochromatin in the rDNA region. This, in turn, inhibits ribosome formation and decreases protein expression in general, which protects cells from energy deprivation-dependent apoptosis (Murayama et al. 2008) and, facilitates repair. Moreover, SIRT1 can deacetylate TBP [TATA-box-binding protein]-associated factor I 68 $\left(\mathrm{TAF}_{\mathrm{I}} 68\right)$ impairing its DNA-binding activity, and in this way, inhibiting RNAPolI-dependent transcription of rDNA (Muth et al. 2001). In addition to Suv39h1, SIRT1 can modulate the activity of p300 histone acetyltransferase. SIRT1 inhibits p300 activity by deacetylating K1020 and K1024 (Bouras et al. 2005). In this way it contributes to the decreased level of histone acetylation.

SIRT2 participates in formation of metaphase chromosomes via H4K16 deacetylation (Vaquero et al. 2006). The level of SIRT2 fluctuates during cell cycle reaching its peak at the $\mathrm{M}$ phase and $\mathrm{G} 2 / \mathrm{M}$ transition (Vaquero et al. 2006). Overexpression of SIRT2 can delay mitotic exit (Dryden et al. 2003).

SIRT3, as the main mitochondrial deacetylase, plays an important role in homeostasis of these organelles. Under stress the nuclear fraction of SIRT3 can deacetylate $\mathrm{H} 4 \mathrm{~K} 16$ and $\mathrm{H} 3 \mathrm{~K} 9$ regulating expression of genes involved in mitochondrial biogenesis and metabolism (Scher et al. 2007). Moreover, no hyperacetylation is observed in SIRT3 ${ }^{-1-}$ cells, which suggests that SIRT3 is involved in regulation of only specific genes or regions (Scher et al. 2007).

SIRT6 is a deacetylase as well as ADP-ribosylase acting mainly on histones. This sirtuin deacetylates $\mathrm{H} 3 \mathrm{~K} 9$ in the promotor regions of, among others, genes involved in metabolism (Zhong et al. 2010). In MEF and ES cells derived from SIRT6 knockout mice, H3K9 hyperacetylation in telomeres was observed. Such hyperacetylation caused a decrease in the level of trimethylated $\mathrm{H} 3 \mathrm{~K} 9$ in telomeres and chromatin relaxation in these regions. This suggests that SIRT6 can protect cells from telomere dysfunction (Cardus et al. 2013). In particular, SIRT6 deacetylates H3K9 in telomere regions in response to DNA damage (Gertler and Cohen 2013), which results in tightening and stabilization of the telomere structure. SIRT6 telomere binding is dynamic, and the strongest interaction is observed during the $\mathrm{S}$ phase of the cell cycle (Michishita et al. 2008). Moreover, SIRT6 stabilized ATP-dependent helicase WRN and prevented telomere dysfunction during DNA replication (Gertler and Cohen 2013). SIRT6 substrates also include H2BK12 and H3K56, increased acetylation level of the latter is associated with genomic instability (Jiang et al. 2013; Gertler and Cohen 2013). The role of SIRT1 and SIRT6 in chromatin condensation is presented in Fig. 1.

SIRT7 interacts with promoter as well as transcribed regions of rDNA genes. This sirtuin deacetylates histones, in particular $\mathrm{H} 2 \mathrm{~A}$ and $\mathrm{H} 2 \mathrm{~B}$ (Ford et al. 2006), however, its main substrate is H3K18 (Barber et al. 2012). Deacetylation of this histone is associated with repression of tumor suppressor genes. Therefore, SIRT7 can support cancer phenotype by inhibiting expression of tumor suppressors. However, it must be noted that SIRT7 is required only to sustain cancer phenotype and does not promote oncogenic transformation of normal cells (Barber et al. 2012; Kim et al. 2013).

\section{Influence on DNA damage and DNA repair}

Unrepairable DNA damage is believed to be one of the basic causes of cellular senescence (Sedelnikova et al. 2004). Already in yeast it was observed that Sir2 takes part in DNA repair. Changes in the localization of Sir2 occur not only during senescence but also as a result of DNA damage. Sir2 dissociates from HM loci and moves to the sites of DNA breaks (Oberdoerffer et al. 2008). This has two effects: firstly, it induces expression of HM genes (involved in DNA damage repair) and secondly, inhibits proliferation giving time for DNA repair to occur. Moreover, at sites of DNA breaks, Sir2 deacetylates histones and DNA damage response proteins that recruit proteins responsible for DNA damage repair (Oberdoerffer et al. 2008). The involvement of sirtuins in DNA damage recognition and repair has been also observed in more complex organisms.

Under normal conditions SIRT1 is bound to hundreds of gene promoters in the mouse genome. The binding pattern is disturbed as a result of genotoxic stress as SIRT1 moves to DNA damage sites where it plays an important role in the recruitment and activation of repair proteins (Chung et al. 2010). In cells derived from SIRT1 knockout mice, aside from chromosomal aberrations, impaired DNA damage repair was observed further proving that this sirtuin is involved in double helix repair (Wang et al. 


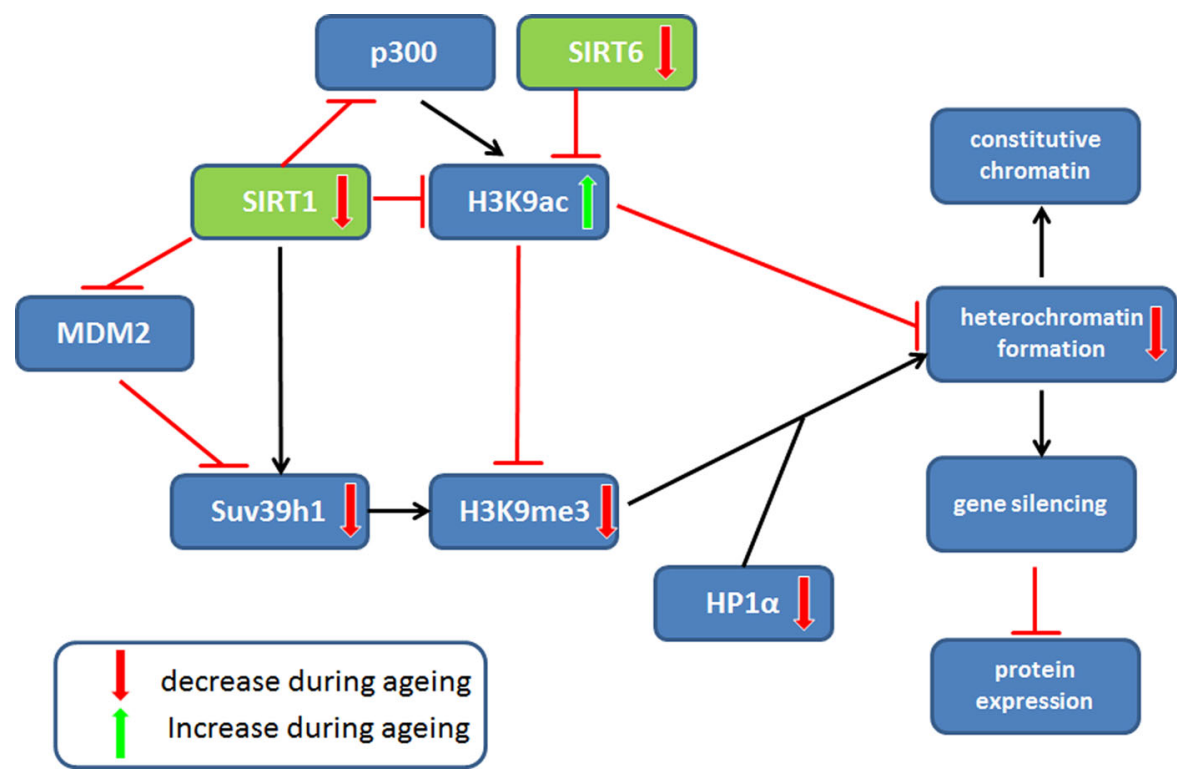

Fig. 1 Role of SIRT1 and SIRT6 in chromatin condensation. SIRT1 and SIRT6 promote formation of heterochromatin in three ways. Firstly, both of the sirtuins deacetylate H3K9 enabling its trimethylation and subsequent binding of HP1 $\alpha$ indispensable for heterochromatin formation. Secondly, SIRT1 decreases activity of p300 histone acetyltransferase. Lastly, SIRT1 activates Suv39h1 methyltransferase by deacetylating

2008). SIRT1 interacts directly with NBS1 and maintains it in a hypoacetylated state, which allows for phosphorylation of S343 that is necessary for efficient DNA damage repair response and activation of the S-phase checkpoint (Yuan et al. 2007). Acetylation of WRN promotes its translocation to the nucleus while subsequent deacetylation by SIRT1 increases its activity and efficiency of DNA damage repair by $\mathrm{HR}$ ( $\mathrm{Li}$ et al. 2008). In response to DNA damage $\mathrm{Ku} 70$ is acetylated on multiple lysine residues. This facilitates dissociation of $\mathrm{Ku} 70$ from BAX, which results in translocation of the latter to the mitochondria and induction of apoptosis. SIRT1 deacetylates Ku70 sustaining its interaction with BAX. This, in turn, inhibits apoptosis and facilitates Ku70-dependent DNA damage repair (Bosch-Presegué and Vaquero 2011). A similar role was shown for SIRT3. SIRT1 is also involved in the repair of single strand DNA breaks via nucleotide excision repair (NER). UV radiation (NER is the main pathway responsible for repair of UV-induced breaks) stimulates interaction of SIRT1 with xeroderma pigmentosum group A (XPA) — one of the key factors in NER. XPA recognizes DNA damage and recruits proteins
K266 in its catalytic domain. Moreover, SIRT1 inhibits polyubiquitination of Suv39h1 by MDM2 and prevents its degradation. Arrows indicate positive regulation. Lines with $T$ shaped ending indicate inhibition. Thick upward and downward arrows inside boxes indicate increase or decrease during aging, respectively. (Color figure online)

essential for the repair process. SIRT1 deacetylates XPA on K63 and K67 facilitating its interaction with RPA32 (which stabilizes single-stranded DNA) and DNA damage repair (Fan and Luo 2010). Additionally, SIRT1 overexpression in mice inhibits telomere erosion while its silencing accelerates telomere shortening (Palacios et al. 2010).

SIRT6 also plays a considerable role in DNA repair and maintenance of genomic stability by integrating signals of DNA damage with activation of repair enzymes (Mao et al. 2011). This sirtuin is involved in $\mathrm{HR}$, non-homologous end-joining (NHEJ) as well as base excision repair (BER) (Mostoslavsky et al. 2006). SIRT6 poly-ADP-ribosylates proteins localized in the vicinity of DNA breaks promoting recruitment of repair enzymes (Gertler and Cohen 2013). Moreover, in response to DNA damage SIRT6 dynamically binds to chromatin and induces global decrease in $\mathrm{H} 3 \mathrm{~K} 9$ acetylation. In this way it stabilizes the binding to DNA of the catalytic subunit of DNA-dependent protein kinase (DNA-PKcs) — a key component of NHEJ that facilitates the access of repair enzymes to double strand breaks. In response to oxidative stress SIRT6 mono-ADP-ribosylates K521 of PARP-1 
increasing its activity and facilitating DNA repair via NHEJ and HR (Beneke 2012). SIRT6 increases the activity of $\mathrm{C}$-terminal binding protein interacting protein (CtIP) — an enzyme responsible for excision of damaged DNA fragments during HR. Under normal conditions CtIP is acetylated, however, after DNA damage SIRT6 deacetylates it on K432, K526 and K604 promoting resection of damaged fragments (Kaidi et al. 2010). It was shown that SIRT6 is also indispensable for BER to occur, however neither direct interaction with any of the components involved in this pathway nor co-localization on the damage site were proven (Mostoslavsky et al. 2006; Tennen and Chua 2011).

The negative feedback loop between DNA damage and NAD+ level may also contribute to cell senescence. DNA damage can induce a decrease in the level of NAD+ due to increased PARP1 activity, which requires NAD+ as a co-factor. Repeated or chronic DNA damage can result in substantial depletion of $\mathrm{NAD}+$ and decrease in sirtuin activity. This in turn, can disrupt DNA damage repair (causing increase in the number of DNA breaks) and impair mitochondria function. The latter may result in increased ROS production and further DNA damage (Imai and Guarente 2014). Therefore, NAD+ level and sirtuin activity can provide an interface between DNA damage and mitochondria function and combine DNA damage theory with Harman's mitochondrial theory of ageing.

Not only direct involvement in DNA repair is important, as in the case of SIRT1 or SIRT6, which can modify a variety of proteins engaged in repair of DNA damage. Glucose and glutamine metabolism is also relevant in this process. Glutamine is the main nitrogen donor, not only for protein, but also nucleotide synthesis. SIRT4 plays an important role in DNA damage response by regulating mitochondrial glutamine metabolism. During DNA damage response SIRT4 inhibits the transport of intermediates to the Krebs cycle so that the nitrogen atom from glutamine can be used for the synthesis of purine nucleotides crucial in DNA repair process (Jeong et al. 2013). SIRT4 is also a negative regulator of glutamate dehydrogenase (GDH), the first enzyme in glutamine metabolism (Haigis et al. 2006). Lack of SIRT4 disturbed DNA damage repair and promoted accumulation of the damage, while SIRT4 overexpression supported the removal of $\gamma \mathrm{H} 2 \mathrm{AX}$ foci (Jeong et al. 2013).
Influence on oxidative stress and energy metabolism

Among sirtuins the most important role in antioxidative defense is played by SIRT3. Deacetylation of mitochondrial complex I and III by SIRT3 results in an increase in the efficiency of electron transport, which prevents ROS production (Haigis et al. 2012). Loss of this sirtuin results in hyper-acetylation of the components of mitochondrial complex I and a decrease in its activity and in ATP level (Ahn et al. 2008). Sirtuins can counteract oxidative stress also by modulating antioxidant enzymes. SIRT1 can influence the level of manganese superoxide dismutase (MnSOD) via cooperation with FOXO transcription factors. Deacetylation of FOXO3a by SIRT1 leads to an increase in the level of MnSOD and catalase (Chung et al. 2010), while recruitment of SIRT1 to the promoter region of MnSOD gene along with FOXO1 is indispensable to co-activate expression of this antioxidant enzyme (Daitoku et al. 2004). Sirtuins modulate not only the level of antioxidant enzymes but also their activity. It was shown that deacetylation of isocitrate dehydrogenase (IDH2) and of MnSOD on K122 by SIRT3 increases activity of these enzymes (Bell et al. 2011). Moreover, activity of SOD1 increased after desuccinylation by SIRT5 (Lin et al. 2013).

Interactions with other proteins involved in senescence

\section{Interaction with $p 53$}

Regulation of SIRT1 and p53 activity is mutual and complicated. In response to stress SIRT1 deacetylates p53 on K320, K373 and K382 in the C-terminal regulatory domain. Deacetylation inhibits p53-dependent transcription and apoptosis, which facilitates DNA damage repair (Cheng et al. 2003). It was shown that SIRT1 colocalizes with p53 in PML nuclear bodies where it antagonizes PML-induced acetylation of p53 and inhibits premature senescence (Langley et al. 2002). SIRT1 can also regulate localization of p53. In mouse embryonic stem cells SIRT1 deacetylates p53 on K379 in response to oxidative stress, which prevents its translocation to the nucleus. This results in an increase in p53 level in the cytoplasm and in mitochondrial-dependent apoptosis (Han et al. 2008). However, in SIRT1 knockout animals, the 
effects associated with modulation of p53 activity are not observed. This inconsistency can be explained by a redundant action of sirtuins-SIRT2 and SIRT3 can also interact with p53 (see below). SIRT2 can inhibit the activity of p53. It is suggested that SIRT3 can act as a regulator in p53-dependent senescence by inhibiting p53 ability to promote cell cycle arrest and senescence ( $\mathrm{Li}$ et al. 2010).

The sirtuins-p53 interaction is reciprocal and also p53 can influence the activity of these enzymes. In the promoter region of SIRT1 and SIRT2 there are two p53-binding sites (Bosch-Presegué and Vaquero 2011; Anwar et al. 2016). Moreover, $3^{\prime}$ UTR fragment of SIRT1 mRNA has a miR-34a-responsive element. miR-34a is a small noncoding RNA that can inhibit expression of some proteins. Active p53 can induce expression of miR-34a. Therefore, increased activity of p53 increases the level of miR-34a, which inhibits SIRT1 translation. This interplay can in part explain the decrease in SIRT1, which we and others observed during cellular senescence (see Grabowska et al. 2015 and Grabowska et al. 2016). There is also indirect interplay between SIRT1 and p53 activity. Both proteins depend on NAD+ level since sirtuins require it as a co-factor while NAD+ can bind to p53 tetramers and affect their conformation thus preventing DNA binding (McLure et al. 2004). p53 can also positively regulate the level of SIRT6 (Kanfi et al. 2008).

\section{Interaction with FOXO family}

FOXO transcription factors are believed to promote longevity although the precise mechanism in not yet fully understood. However, it has been shown that they act as sensors of the insulin/IGF-1 signaling pathway, which is crucial for ageing and longevity (Martins et al. 2016), and regulate expression of key antioxidant enzymes such as MnSOD and catalase (see above). Activity of the FOXO family can be regulated by phosphorylation and acetylation. Acetylation of these factors facilitates phosphorylation and inactivation therefore decreases their ability to bind to DNA (Matsuzaki et al. 2005). Sirtuins can deacetylate some members of the FOXO family such as FOXO1, FOXO3a and FOXO4 whereby inducing their activity (Michan and Sinclair 2007). It has been shown that deacetylation of FOXO3a increases expression of proteins involved not only in protection against oxidative stress but also in DNA repair and cell cycle checkpoints (Michan and Sinclair 2007). SIRT2 was demonstrated to be the main deacetylase of cytoplasmic FOXO1 (Zhao et al. 2010). On the other hand, FOXO1 can regulate expression of SIRT1 by binding to its gene promoter region (Xiong et al. 2011), which creates an autoregulatory feedback loop regulating SIRT1 expression.

\section{Interaction with $N F \kappa B$}

$\mathrm{NF \kappa B}$ transcription factor was shown to regulate the process of ageing and it seems that its main role is to transactivate genes the products of which contribute to the senescence associated secretory phenotype (SASP). It was shown that SIRT1 (and also SIRT2) can inhibit NFKB signaling by deacetylating p65 (RELA) on K310, which modulates its ability to bind DNA and induces transcription of proteins involved in inflammation. In consequence, SIRT1 activity leads to a decrease in inflammation (Chung et al. 2010). SIRT6 can also inactivate NFKB by direct interaction with its RELA subunit. Such effect is followed by inhibition and destabilization of RELA binding at target gene promoters (Gertler and Cohen 2013), which can contribute to inhibition of apoptosis and senescence. Moreover, SIRT6 destabilizes binding of this transcription factor by deacetylating $\mathrm{H} 3 \mathrm{~K} 9$ in gene promoters of NFKB target genes (Gertler and Cohen 2013). On the other hand, NFKB can decrease the activity of SIRT1, in a similar way to p53, by modulating miR-34a expression (Kauppinen et al. 2013).

\section{Interaction with $A M P K$}

Many studies revealed that increased AMPK (AMPactivated protein kinase) activity can extend the lifespan of some model organisms. It was also shown that AMPK can regulate several signaling pathways involved in senescence and ageing such as those engaging p53, mTOR and NFKB (Salminen and Kaarniranta 2012). Moreover, AMPK can regulate cellular energy expenditure/status through modulation of NAD+ level, which suggests that this kinase may be involved in regulation of sirtuin activity. Both AMPK and SIRT1 are activated as a result of CR, have similar molecular targets and biological activities (Ruderman et al. 2010). Activation of AMPK elevates 
the level of NAD+ (among others through increase in the level and activity of NAMPT) thereby increasing SIRT1 activity (Canto et al. 2009). On the other hand, SIRT1 activation increases the activity of AMPK by LKB1 deacetylation on K48. Deacetylated LKB1 migrates from the nucleus to the cytoplasm, binds to STE20-related adaptor protein (STRAD) and mouse embryo scaffold protein (MO25). The latter interaction induces LKB1 kinase activity and AMPK phosphorylation (Wang et al. 2011). This creates a positive feedback loop. SIRT4, on the other hand, inhibits AMPK activity (Ho et al. 2013).

\section{Interaction with P66shc}

SIRT1 negatively regulates the expression of P66shc (Chen et al. 2013), one of the three isoforms of the ShcA family. This protein is involved in oxidative stress because it stimulates mitochondrial ROS generation, and downregulates antioxidant enzyme synthesis (Miyazawa and Tsuji 2014). It also controls the lifespan/longevity (reviewed in Kong et al. 2016). SIRT1 decreases both the P66shc level and oxidative stress intensity (Zhou et al. 2011) because it binds to the gene promoter of P66shc and deacetylates histone $\mathrm{H} 3$, which reduces the transcription rate. P66shc knockout mice had longer lifespan and enhanced resistance to oxidative stress and age-related pathologies (Berry et al. 2007; Vikram et al. 2014; Kumar et al. 2014b; Ma et al. 2014). Moreover, P66shc inhibits the activity of FOXO3a transcription factor (Miyazawa and Tsuji 2014). Ageing-initiated P66shcmediated endothelial dysfunction was shown both in clinical trials and animal experiments, however, not in P66shc knockout mice (Francia et al. 2004). This suggested that P66shc knockout mice were protected from endothelial dysfunctions. Moreover, such mice had $30 \%$ longer lifespan than control ones. SIRT1 seems to be involved in this protection (Berry et al. 2007). It has been also observed that CR, which evokes an increase in sirtuin activity, could reduce P66shc level (Zhou et al. 2011).

\section{Doubts}

Despite plethora of research documenting beneficial influence of sirtuins on ageing and longevity there are also some conflicting data. Some authors completely exclude sirtuin involvement in CR-induced lifespan extension (as it was shown that CR can extend lifespan of Sir2-deficient yeast) (Tsuchiya et al. 2006). Others state that the fact that Sir2 overexpression combined with CR resulted in greater lifespan extension than each intervention alone suggests that sirtuins do not mediate the positive effect of CR (Kaeberlein et al. 2004). There are studies implying that increased longevity of some model organisms (such as $D$. melanogaster and C. elegans) after sirtuin overexpression is due to a lack of genetic background standardization and incorrectly matched controls (Burnett et al. 2011). Some data also show that SIRT1 can promote replicative senescence. Mouse embryonic fibroblasts lacking SIRT1 are characterized by increased replicative potential under conditions of chronic sublethal stress (Chua et al. 2005).

One of the reasons for such contradictory data can be the context-dependency of sirtuins. Activity of these deacetylases depends on the tissue and/or experimental conditions e.g. the presence of stress. The impact of sirtuin level was emphasized in the study of Alcendor et al. (2007). It was shown that 2.5-7.5 fold increase in SIRT1 level in mouse heart prevented age-associated cardiac hypertrophy, apoptosis, cardiac dysfunction and expression of senescence markers such as p15INK4b, p19ARF, p53. On the other hand, 12.5 fold increase in SIRT1 level promoted cardiac hypertrophy, induced apoptosis and promoted cardiomyopathy. The authors suggested that the beneficial effects could be the consequence of oxidative stress modulation since low and moderate overexpression of SIRT1 protects against oxidative stress, by eliciting an increase in the level of antioxidant enzymes and proteins such as catalase, heat shock proteins (Hsp40, Hsp70 and Hsp90), telomere repeat binding factor 2 (TRF2) and telomere reverse transcriptase (TERT). On the other hand, high SIRT1 level increased oxidative stress. High level of NAD+ dependent deacetylase can deplete the pool of this vital PARP1 cofactor and in this way impair DNA repair and mitochondrial respiration followed by decreased ATP production. Importantly, mice with moderate SIRT1 overexpression did not exhibit extended lifespan, while high sirtuin level shortened the animal life expectancy to a half. There is also a discrepancy of opinions as to SIRT1 contribution to atherosclerosis progression. It seems that the role of SIRT1 in this process depends on the cellular/physiological context as there are reports suggesting its 
protective function, and those implying promotion of plaque formation (Watroba and Szukiewicz 2016).

Intervention in organismal ageing by sirtuin regulation

It has been proven that ageing is an extremely plastic process and its modulation can be very efficient. Ageing can be accelerated, slowed down, and, in some cases, even stopped or reversed under certain experimental conditions (Fahy et al. 2010). Anti-ageing interventions delay and prevent age-related disease onset. They include behavioral, dietary and pharmacological approaches. Also, many protein targets and many drugs are being tested for their effects on healthspan and lifespan. The intervention strategies include: (1) dietary interventions mimicking chronic dietary restriction, (2) inhibition of the mTOR-S6K pathway, (3) inhibition of the GH/IGF1 axis and (4) drugs that activate AMPK or specific sirtuins (Longo et al. 2015). In fact, all of the mentioned approaches are related to sirtuins. These enzymes are involved in mimicking dietary restriction, as it has been shown, for example, for resveratrol. Furthermore, inhibition of the mTOR-S6K pathway is caused by AMPK, which is regulated by sirtuins. In turn, the SIRT1-p53 pathway has been described to antagonize IGF-1induced premature cellular senescence (Tran et al. 2014). Therefore sirtuins are extensively studied in the context of their role in alleviating symptoms of ageing and age-related diseases (Houtkooper et al. 2012; Hall et al. 2013; Poulose and Raju 2015).

\section{Dietary restriction}

Dietary/caloric restriction (DR)/(CR) (the reduction of calorie intake without causing malnutrition) is the only known intervention able to increase the lifespan in many species, including yeast, fruit flies, nematodes, fish, rats, mice, hamsters and dogs (Weindruch 1996; Masoro 2005; Ingram and Roth 2015) and possibly even primates (Ingram et al. 2006; Colman et al. 2009). Much research has suggested that lifespan extension and healthspan improvement brought by caloric restriction are mediated by mechanisms involving sirtuins. For example, some of the effects of caloric restriction in flies, worms and mammals have been shown to be mediated by SIRT1 (Rogina and Helfand 2004; Tissenbaum and Guarente 2001;
Chen et al. 2005; Boily et al. 2008). Diet-induced aortic stiffness, developed within 2 months in mice fed HFD (high fat diet), can be prevented by SIRT1 induction in VSMC (Fry et al. 2016). Reduction of arterial stiffness can be also achieved by overnight fasting in mice fed HFD for 2 or 8 months but not in mice lacking functional SIRT1 in VSMC. Similar effect was observed after SIRT1 overexpression or treatment with SIRT1 activators. DR was also shown to induce SIRT6, which delayed ageing by suppressing NFKB signaling in aged mice after 6-month treatment or in cells cultured in low glucose condition (resistance to cellular senescence) (Zhang et al. 2016b). Dietary restriction is one of the most promising strategies for increasing lifespan and healthspan also in humans (reviewed in Longo et al. 2015). In humans such interventions are effective in lowering the prevalence of age-related loss of function and protecting against age-related pathologies, as evidenced by changes in the level of markers for type 2 diabetes, hypertension, cardiovascular disease, cancer, and dementia (Cava and Fontana 2013). Because long lasting DR is not recommended for most people and could be associated with undesirable side effects, less drastic dietary interventions should be considered and therefore drugs or supplements, which mimic the effects of DR are searched for. A promising strategy, potentially useful for humans, could be short-term fasting that could mimic DR. Because sirtuins can mediate many of the beneficial effects of DR (Satoh et al. 2013), therefore activators of the sirtuin pathway are very attractive candidates considered to mimic DR. To such compounds belongs resveratrol, the role of which in DR is well recognized and described (Chung et al. 2012), and probably also curcumin as has recently been shown by us (Grabowska et al. 2016).

\section{mTOR inhibition}

Inhibitors of the mTOR signaling are the major candidates for targeted interventions. This signaling pathway has been linked to lifespan and healthspan extension in model organisms (Johnson et al. 2013) because reduced mTOR signaling benefited both these phenomena. The best recognized inhibitor of $\mathrm{mTOR}$ is rapamycin, although a long term treatment can bring about some side effects (Hartford and Ratain 2007). S6 kinase (S6K) is a target of mTOR. Loss of S6K promoted longevity in yeast, flies, worms, and mice 
(Johnson et al. 2013). Sirtuins and AMPK are regulators of this kinase. It has been shown that increased SIRT1 activity resulting from resveratrol diet supplementation inhibited the mTOR/S6K pathway in mice (Liu et al. 2016).

\section{Attenuation of IGF1/insulin signaling pathway}

The IGF1/insulin signaling pathway is a very well recognized target in postponing ageing. In mammals upstream of IGF1 is a growth hormone (GH) (BrownBorg and Bartke 2012). GH mutant mice (a reduction of plasma levels or disruption of the receptor) live $50 \%$ longer than wild-type ones. GH fulfills key metabolic functions, controls circulating IGF1 levels and acts also independently of IGF1. The insulin and IGF1 signaling pathway is strongly evolutionarily conserved. Both insulin and IGF are important in the maintenance of proper metabolism and organismal homeostasis. They control growth, development and regulate stress resistance. Activation of this pathway leads to phosphorylation of transcription factors belonging to the FOXO family. In turn, it has been shown that these transcription factors are required for impairing insulin/IGF-1 signaling to extend lifespan in worms (Kenyon et al. 1993; Melendez et al. 2003). Sirtuins are among the regulators of the transcriptional activity of FOXO proteins. Human IGF-1 receptor gene polymorphisms are associated with exceptional longevity (Suh et al. 2008) and low plasma IGF-1 concentrations predict further survival in long-lived people (Milman et al. 2014). Moreover, treatment with IGF-1 triggered premature cellular senescence (human primary IMR90 fibroblast and MEFs, mouse embryonic fibroblasts) in a p53-dependent manner and a recent study explained this result as being due to attenuation of SIRT1 functioning, followed by enhanced p53 acetylation and stabilization, and premature cellular senescence (Tran et al. 2014). DR is very effective in inhibiting insulin/IGF-1 signaling.

\section{Dietary and pharmacological interventions}

Functional foods and nutraceuticals/dietary ingredients are a great promise for health and longevity promotion and prevention of age-related chronic diseases (Ferrari 2004). The potent sirtuin-activating compounds (STACs) include several classes of plantderived metabolites such as flavones, stilbenes, chalcones, and anthocyanidins, which directly activate SIRT1 in vitro. Several substances are reported to have anti-senescent effect in vitro by modulating the SIRT1 pathway. These compounds include a number of agents such as resveratrol (Kao et al. 2010), cilostazol (Ota et al. 2008), paeonol (Jamal et al. 2014), statins (Ota et al. 2010), hydrogen sulfide (Suo et al. 2013; Zheng et al. 2014) and persimmon (Lee et al. 2008). It is documented that polyphenols, to which curcumin also belongs, are able to modulate sirtuins (reviewed in Jayasena et al. 2013; Chung et al. 2010). The best recognized and described natural compound is resveratrol and there are a lot of papers summarizing its role in sirtuin stimulation on both the organismal and cellular level (Howitz et al. 2003; Ramis et al. 2015). Activation of SIRT1 by resveratrol supplementation led to increased lifespan and improved healthspan of several species i.e., mimicked the anti-ageing effect of DR (Baur et al. 2006; Mouchiroud et al. 2010). In human diploid fibroblasts resveratrol decreased or delayed cellular senescence (Huang et al. 2008). Other natural anti-ageing compounds are: quercetin, butein, fisetin, kaempferol, catechins and proanthocyanidins (reviewed in Jayasena et al. 2013). Several reports emphasized that dietary supplementation of polyphenols may protect against neurodegenerative, cardiovascular, inflammatory, metabolic diseases and cancer by enhancing SIRT1 deacetylase activity. However, in humans, the therapeutic and pharmacological potential of these natural compounds remains to be validated in clinical conditions. Their efficiency is, however, put into doubt because many natural compounds, including curcumin are bad leads for drugs (Baell and Walters 2014). However, polyphenols may act as prophylactic agents in terms of dietary intake rather than as therapeutic ones. Some natural compounds from Traditional Chinese Medicines (TCMs) are potent SIRT1 activators (Wang et al. 2016).

Another compound considered as anti-ageing one is melatonin. It is able to activate sirtuins and it has been observed that its level decreases with age (Ramis et al. 2015). It has been shown that melatonin prevents agerelated alterations in apoptosis in dentate gyrus, which are associated with neurodegeneration, by increasing SIRT1 (Kireev et al. 2013). Adjudin, a derivative of lonidamine, an activator of SIRT3 (Bellizzi et al. 2005; Brown et al. 2013; Kincaid and Bossy-Wetzel 2013), is also considered as an anti-ageing factor (Xia and Geng 2016). Another compound that possesses 
anti-ageing function is icariin, an active ingredient of Epimedium in Berberidaceae (Lee et al. 1995). It is able to enhance the expression of SIRT6 (Chen et al. 2012). A polysaccharide derived from Cornus officinalis could slow down the progression of age-related cataracts by significantly increasing expression of SIRT1 mRNA and FOXO1 mRNA (Li et al. 2014). Oligonol, an antioxidant polyphenolic compound showing anti-inflammatory and anti-cancer properties, mainly found in lychee fruit, may act as an anti-ageing molecule by modulating the SIRT1/autophagy/AMPK pathway (Park et al. 2016). Spleen lymphocytes derived from old mice treated with oligonol showed increased cell proliferation. Moreover, this compound extended the lifespan of C. elegans infected with lethal Vibrio cholera (Park et al. 2016). Also, metformin, a herbal compound widely prescribed as oral hypoglycaemic drug for the treatment of type 2 diabetes, acts by SIRT1 activation (and FOXO1 elevation) in endothelial dysfunction caused by diabetes-related microvascular disease associated with accelerated endothelium senescence and ageing (Arunachalam et al. 2014).

Natural phytochemicals are effective sirtuin activators, but synthetic STACs, such as SRT1720, SRT2104, SRT1460, SRT2183, STAC-5, STAC-9, STAC-10 are considerably more potent, soluble, and bioavailable (Hubbard and Sinclair 2014; Minor et al. 2011). In preclinical models, STACs have shown effectiveness in treating age-related diseases and complications associated with ageing, including cancer, type 2 diabetes, inflammation, cardiovascular disease, stroke, and hepatic steatosis (Hubbard and Sinclair 2014). Based on mouse models, STACs could also be beneficial in neurodegeneration (Alzheimer's or Parkinson's disease) (Zhao et al. 2013; Graff et al. 2013; Hubbard and Sinclair 2014). SRT2104 extended both the mean and maximal lifespan of male mice fed a standard diet and this effect concurred with improved health, including enhanced motor coordination and decreased inflammation (Mercken et al. 2014).

An alternative approach to activating sirtuins is regulation of NAD + level by activating enzymes involved in biosynthesis of NAD or by inhibiting the CD38 NAD hydrolase (Wang et al. 2014; Escande et al. 2013; Braidy et al. 2014). Manipulation of the level of NAD+ leads to variations in the lifespan elongation effect of SIRT1. The compound that can antagonize nicotinamide inhibition of sirtuin deacetylating activity is isonicotinamide (Sauve et al. 2005). Inhibitors of NAM (natural inhibitor of sirtuin) exert the same effect as sirtuin activators (Sauve et al. 2005). Glucose restriction, which mimics DR, extended the lifespan of human Hs68 fibroblasts due to increased NAMPT expression, NAD+ level and sirtuin activity (Yang et al. 2015). In turn, lifespan extension was diminished by inhibition of NAMPT and sirtuins. Moreover, malate dehydrogenase, MDH1, which is involved in energy metabolism and reduces NAD+ to NADH during its catalytic reaction, plays also a critical role in cellular senescence. Its activity is reduced in human fibroblasts derived from elderly individuals and knock down of this enzyme in young fibroblast induces a senescence phenotype (Lee et al. 2012). Decrease in MDH1 and subsequent reduction in NAD/NADH ratio led to SIRT1 inhibition. Mice engineered to express additional copies of SIRT1 or SIRT6, or treated with STACs (resveratrol, SRT2104) or with NAD+ precursors, have improved organ function, physical endurance, disease resistance and longevity (Bonkowski and Sinclair 2016).

Activators of the AMPK pathway are considered as anti-ageing factors. SIRT1 increases the activity of AMPK through LKB1 activation, and, conversely, the activity of sirtuins is stimulated by AMPK. In turn, AMPK downregulates the mTOR pathway by inhibiting of S6K. To AMPK activators belong: 5-aminoimidazole-4-carboxamide riboside (AICAR), biguanides, salicylates, resveratrol, quercetin, catechins and, in certain range of concentrations, also curcumin (Coughlan et al. 2014; Grabowska et al. 2016).

Sirtuins are also responsible for epigenetic modifications (histone and non-histone proteins), which lead to changes in transcriptional activity of many genes. It is proposed that epigenetic factors contribute to ageing. Such factors are regulated by lifestyle, diet and exogenous stress. It is believed that epigenetic modifications (of both histones and DNA) have a comparable impact on gene expression to genetic modifications. It is suggested that manipulation of sirtuins could be beneficial for liefspan/healthspan modulation due to epigenetic changes. In humans, only nontoxic natural substances, such as curcumin or resveratrol, which could lead to histone deacetylation, should be considered for clinical testing as sirtuins activator. In general, functional food is a very 
promising element of anti-ageing intervention, including its potential influence on epigenetic modifications. Modulation of SIRT1 expression may represent a new means to counteract the effect of ageing.

\section{Physical activity}

Regular physical training is able to improve the quality of life. Exercise improves the resistance to oxidative stress, which could influence the pace of ageing and help maintaining the brain function (Marton et al. 2010). Extensive physical activity induces inflammation, increases ROS production and may impair the antioxidant defense system as it has been shown in skeletal muscle and blood (Banerjee et al. 2013). Mildly intense exercise can act as hormetin by eliciting a mild stress, which in turn activates defense mechanisms and brings beneficial effects including reduction of oxidative stress. Chronic exercise reduces oxidative stress by upregulating the activity of antioxidant enzymes (Greathouse et al. 2005). Mild physical activity is a potent activator of sirtuins (Csiszar et al. 2009; Radak et al. 2008). SIRT1 is suggested to be a master regulator of exercise-induced beneficial effects. It has been shown that long-term moderate exercise (36 weeks) induced increase in SIRT1 level in adult rat muscle, liver and heart (Bayod et al. 2012). Also, physical training promoted SIRT1 (as well as AMPK and FOXO3a) activity in muscle tissue in aged rat (Ferrara et al. 2008; Huang et al. 2016; Sahin et al. 2016). Similar effects were also described in humans (Bori et al. 2012). It has been demonstrated that in human skeletal muscle of both young and aged subjects, SIRT1 and AMPK gene expression increase after exercise. Exercise can at least partially recover the adaptive capacity to cope with mild oxidative stress that is lost in ageing and is the most effective intervention against several age-related pathologies such as sarcopenia, metabolic alterations (Pasini et al. 2012), neurodegeneration (Bayod et al. 2011; Mirochnic et al. 2009; Van Praag 2009) and cognitive loss (Kramer et al. 2006). Moderate forced exercise performed from an early age to adulthood has an important long-term impact on animal health. Exercise reduced plasma levels of glucose, cholesterol and triglycerides (Lalanza et al. 2012). In adult and older adult humans moderately intense exercise, for $30 \mathrm{~min}, 5$ days a week, has beneficial effects (Colcombe and Kramer 2003; Rolland et al. 2010; Slentz et al. 2011). Exercise stimulates glucose uptake and mitochondrial biogenesis. Administration of AICAR is able to mimic the effect of physical activity (Hayashi et al. 1998; Song et al. 2002). Physical activity also elevated the level of NAMPT in human skeletal muscle (Costford et al. 2010). Even single bout of exercise increased SIRT1 expression in young individuals but such effect was not observed in old ones (Bori et al. 2012). Beneficial effect of exercise can be also observed at the cellular level. It has been shown that exercise inhibited replicative senescence of adipocytes (Schafer et al. 2016) and decreased the level of apoptosis in rat cardiomyocytes. With age, apoptotic pathway protein expression increases and the expression of the pro-survival p-Akt protein decreases significantly. Exercise increased activity of the IGF1R/PI3K/Akt survival pathway in the heart of young rats, however, in old animals the level of SIRT1 increased as a compensatory mechanism. Moreover, physical activity enhanced the SIRT1 longevity compensation pathway instead of elevating IGF1 survival signaling and in this manner improved cardiomyocyte survival (Lai et al. 2014). Physical activity is able to reduce the harmful effects of a fast food diet (FFD), prevent premature senescent cell accumulation and appearance of SASP in mice adipose tissue (Schafer et al. 2016). This suggests that exercise may provide restorative benefit by mitigating accrued senescent burden.

As mentioned above, sirtuin activation (by phytochemicals, CR, exercise, etc.) elicits an adaptive response to continuous mild exposures to stressors, in agreement with the hormesis principle (Bhakta-Guha and Efferth 2015). The involvement of sirtuins in lifespan/healthspan elongation strategies is summarized in Fig. 2.

Curcumin in sirtuins regulation

Curcumin is a natural polyphenol extracted from a yellow pigment spice plant, turmeric, used for millennia in traditional medicine. Some polyphenols activate SIRT1 directly or indirectly, as has been shown in a variety of research models (Queen and Tollefsbol 2010). It has been proposed that curcumin possesses multiple biological properties including anti-oxidant, anti-inflammatory and anti-cancer activity, however there is also some rationale to consider this compound as an anti-ageing factor (Sandur et al. 


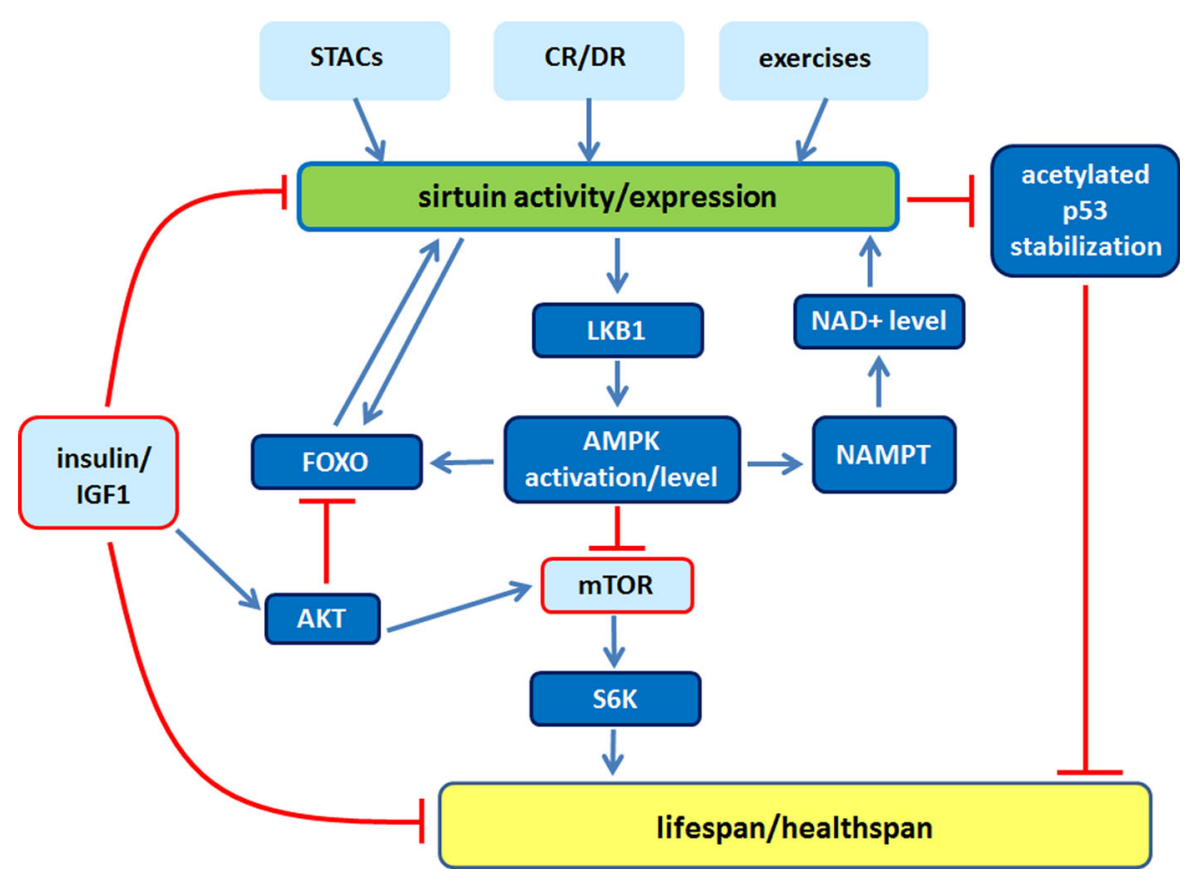

Fig. 2 Involvement of sirtuins in lifespan/healthspan elongation pathways. Sirtuins modulate multiple pathways involved in mediating positive effects of some anti-ageing interventions, such as calorie/diet restriction (CR/DR) or exercise. Such effect can also be mimicked by sirtuin activating compounds (STACs). Prolonged activation of IGF1 pathway, involving PI3K-AKT, leads to phosphorylation and inhibition of FOXO and to inhibition of SIRT1 activity resulting in increased level of acetylated p53. Acetylation stabilizes p53, increases its activity and leads to premature cell senescence. Sirtuins contribute to life extension in animals with overactivated insulin/IGF1

2007; Sikora et al. 2010a, b; Salvioli et al. 2007). Curcumin was able to extend the lifespan of such organisms as fruit fly, nematodes and mice, and alleviated symptoms of some diseases including agerelated ones (Liao et al. 2011). It reduced the impact of some harmful factors such as radiation or chemicals. Moreover, it increased the ability of cells to differentiate during replicative senescence as it was show in human epidermal keratinocytes (Berge et al. 2008). Curcumin possesses numerous target proteins and there are data showing that it is able to act by sirtuin activation. Several studies note that pretreatment with curcumin significantly enhances SIRT1 activation and attenuates oxidative stress (Sun et al. 2014; Yang et al. 2013). For example, pretreatment with curcumin attenuated mitochondrial oxidative damage induced by myocardial ischemia reperfusion injury through activation of SIRT1 (Yang et al. 2013). Likewise, curcumin blocked the neurotoxicity of amyloid-beta in signaling by increasing FOXO activity. Furthermore, sirtuins activate LKB1/AMPK pathway by deacetylating LKB1. AMPK downregulates mTOR/S6K activity preventing onset of senescence in cell cycle arrested cells. Moreover, AMPK can increase NAMPT activity, the enzyme indispensable in a salvage pathway, leading to NAD+ upregulation, which promotes sirtuin activity. Arrows indicate positive regulation. Lines with $T$-shaped ending indicate inhibition. Targets of lifespan/ healthspan strategies are in light color boxes. Light color boxes with frame-pathways to be inhibited, without frame-beneficial activities. (Color figure online)

rat cortical neurons by the same mechanism (Sun et al. 2014). The protective properties of curcumin, owed to the induction of sirtuins, help to reduce cisplatin chemotherapy-induced nephrotoxicity (Ugur et al. 2015) and protect kidney from gentamicin-induced acute kidney injury in animals (He et al. 2015). It has been shown that curcumin can elongate the lifespan of Caenorhabditis elegans but not when Sirt2 (the homolog of mammalian SIRT1) is mutated (Liao et al. 2011). Moreover, curcumin increased the level of SIRT1, which could help to prevent muscle damage (Sahin et al. 2016). Data concerning the impact of curcumin on cellular senescence are, however, confusing. On the one hand, it has been shown that curcumin attenuates hydrogen peroxide-induced premature senescence in HUVECs via activation of SIRT1 (Sun et al. 2015). Moreover, it was demonstrated that another curcuminoid, bisdemethoxycurcumin, could also antagonize the oxidative stress- 


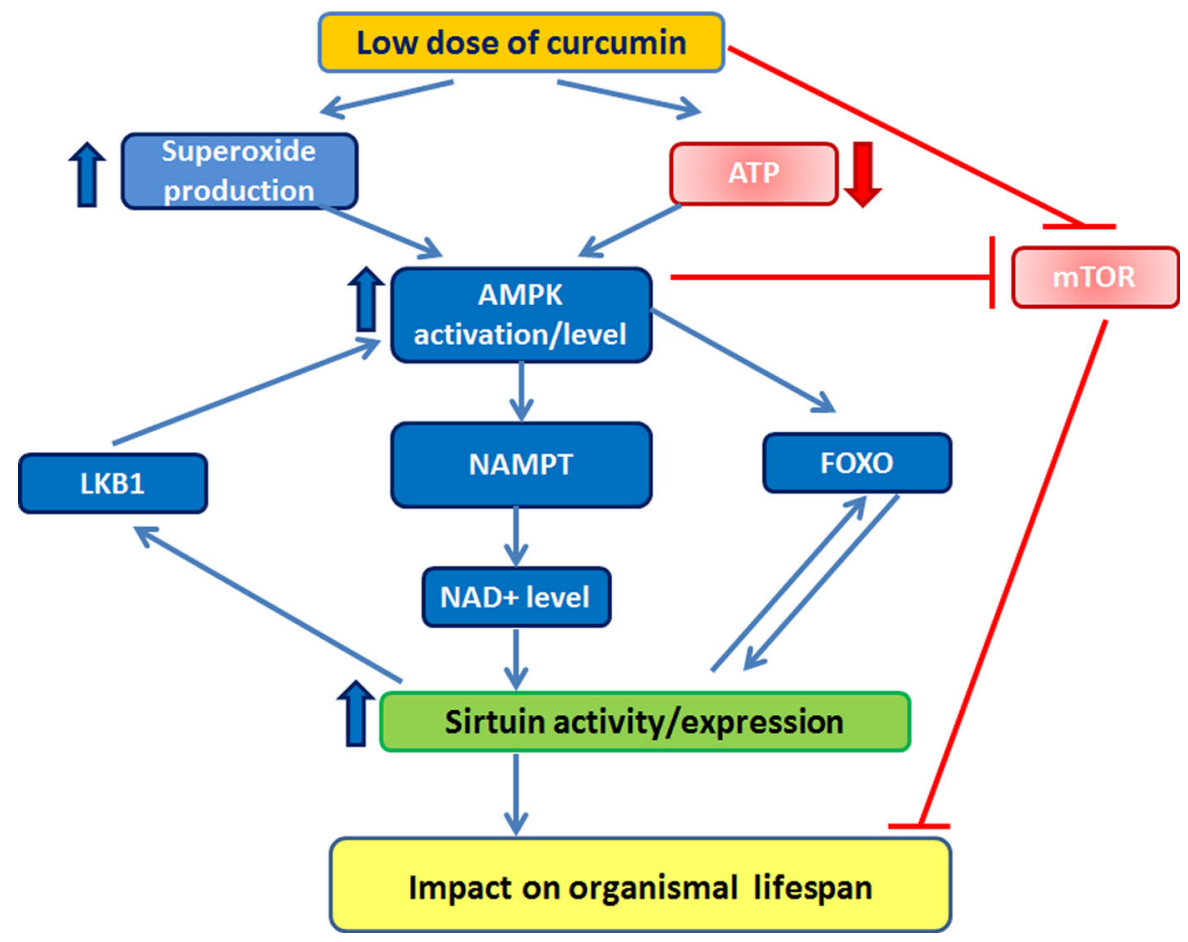

Fig. 3 Mechanism of sirtuin activation by curcumin. We propose that curcumin increases sirtuins level and activity through upregulation and activation of AMPK. Such action can be a result of ATP reduction and initial increase in superoxide production (which is later neutralized by elevated expression of antioxidant enzymes). AMPK activation promotes NAD+ production via increase in NAMPT activity. Moreover, AMPK activates FOXO transcription factors which can induce sirtuin expression. Upregulation and activation of sirtuins promote

induced premature senescence in WI38 fibroblasts through activation of the SIRT1/AMPK signaling pathway (Kitani et al. 2007). On the other hand, we showed that curcumin did not protect cells building the vasculature from premature senescence induced by DNA damaging agent, doxorubicin and did not postpone replicative senescence despite SIRT1 and AMPK upregulation (Grabowska et al. 2016). It is difficult to adjudicate whether curcumin can protect cells from senescence in vivo, but its role in sirtuin stimulation is convincing. Moreover, a lot of data show the reduction of symptoms of age-related diseases as a result of curcumin treatment. In particular, beneficial role of curcumin in the cardiovascular system is supported by numerous research data (Srivastava and Mehta 2009; Olszanecki et al. 2005; Yang et al. 2006). An animal study demonstrated that curcumin supplementation significantly ameliorated
LKB1/AMPK activity creating a positive feedback loop. Additionally, curcumin can contribute to postponing of ageing by inhibiting AKT/mTOR pathway. Thin arrows indicate positive regulation. Lines with $T$-shaped ending indicate inhibition. Thick arrows indicate decreasing or increasing level as described in Grabowska et al. (2016). The level/activity of proteins in dark color boxes increased upon curcumin supplementation, in light color boxes, decreased. (Color figure online)

arterial dysfunction and oxidative stress associated with ageing (Fleenor et al. 2013). It seems justified to consider curcumin as a beneficial anti-pathological factor in the cardiovascular system. The neuroprotective role of curcumin is also mediated by SIRT1 induction, observed in primary cortical neurons in vitro. Accumulation of extracellular glutamate, the most abundant neurotransmitter in the brain involved in synaptic plasticity, learning, memory and other cognitive functions, can provoke neuronal injuries. Curcumin protected cortical neurons against glutamate excitotoxicity by SIRT1-mediated deacetylation of PGC- $1 \alpha$ and preservation of mitochondrial functioning (Jia et al. 2016).

The effect of curcumin action strongly depends on its concentration. Curcumin belongs to hormetins, which means that at low concentration it may exert beneficial effects but is harmful at high concentrations 


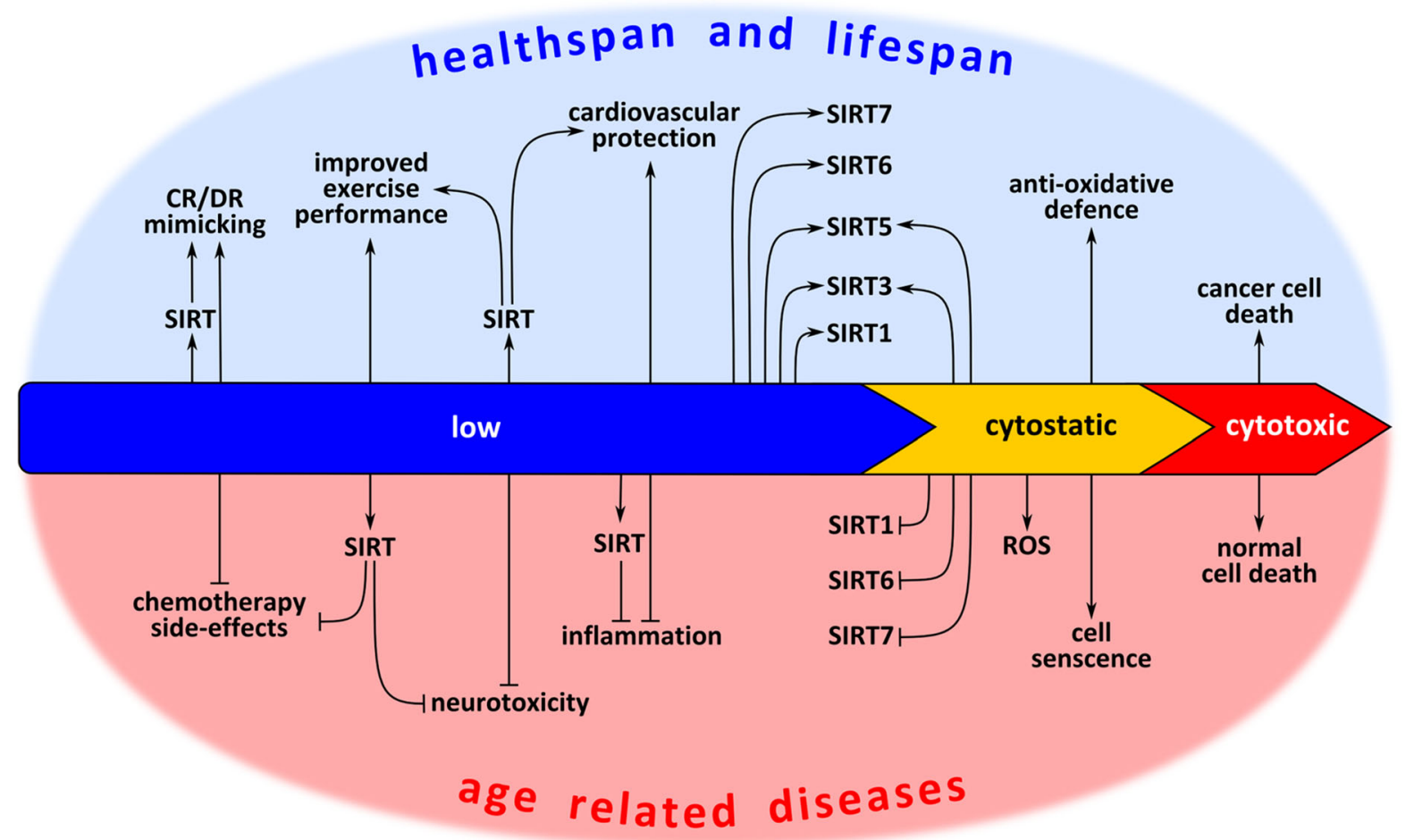

Fig. 4 Dose-dependent activity of curcumin. Curcumin in high concentrations can be toxic while low concentrations may exert beneficial effects. In cytotoxic concentrations curcumin can be useful for eliminating cancer cells (a beneficial role), but may induce cell death in normal cells (a detrimental role). Cytostatic doses of curcumin induce senescence both in cancer and primary cells. In some situations this could be beneficial (senescence of cancer cells, protection from atherosclerosis), in others on the contrary (premature senescence of primary cells). Senescence upon curcumin treatment is associated with increased ROS production, upregulation of mitochondrial sirtuins (sirtuin 3 and

(Calabrese 2014; Demirovic and Rattan 2011). Hormetins, by inducing a mild stress, and in consequence hormesis, are considered to be a promising strategy to slow down ageing and prevent or delay the onset of age-related diseases (Rattan 2012). The sensitivity to curcumin depends on cell type and probably the phase of the cell cycle. In vitro, in a certain range of concentrations, curcumin is toxic for all cell types, in another range inhibits the cell cycle and, at lower concentrations, seems to have no visible impact on cells (potentially beneficial doses according to the hormetic activity of curcumin). We showed that cytostatic doses of this factor induced cellular senescence in cancer cells (Mosieniak et al. 2012, 2016) and in cells building the vasculature (Grabowska et al.
5), decrease in the level of sirtuins 1, 6 and 7 and upregulation of proteins involved in anti-oxidative defense. In turn, in low doses curcumin is able to upregulate the level of sirtuins. Animal studies show that supplementation of diet with curcumin can attenuate symptoms of some age-related diseases and improve exercise performance. Such effect is elicited via direct influence of curcumin on processes such as inflammation and/or indirectly via sirtuin upregulation and activation. Arrows indicate positive regulation. Lines with $T$-shaped ending indicate inhibition. Low, cytostatic and toxic refer to the range of curcumin concentrations

2015). Curcumin-induced senescence of both vascular smooth muscle (VSMC) and endothelial (EC) cells was associated with decreased level of SIRT1 and SIRT6. Such downregulation seems to be characteristic for cell senescence not for curcumin. On the other hand, the level of mitochondrial SIRT3 and SIRT5 increased after curcumin treatment. These enzymes are stimulated in response to stress conditions and SIRT3, in particular, is an anti-oxidative protein which increases the activity of e.g. MnSOD. We postulate that activation of mitochondrial sirtuins is characteristic for dual curcumin action and could be considered as a protective mechanism induced by increased ROS production. Curcumin simultaneously increased ROS generation and activated proteins involved in anti- 
oxidative defense. This compound has also an impact on SIRT7. Downregulation of SIRT7 was observed at cytostatic concentration of curcumin. This could explain the arrest of the cell cycle, because it was documented that downregulation of SIRT7 may stop cell proliferation (Ford et al. 2006). Decreased activity of SIRT7 is associated with induction of nucleolar stress, which is related to inhibition of rDNA transcription (Lewinska et al. 2015). In turn, low doses of curcumin did not impair SIRT7 expression and even slightly increased its level (Grabowska et al. 2016). We tested also such concentrations of curcumin which have no impact on the proliferation of cells building the vasculature. We expected that such doses could delay the symptoms of cellular senescence, however, our results excluded this possibility, even though we observed that curcumin was able to increase sirtuin level, namely that of sirtuin 1, 3, 5, 6 and 7 (Grabowska et al. 2016). Therefore we concluded that curcumin anti-ageing activity is not due to delaying cellular senescence but is rather related to sirtuin elevation.

It has been demonstrated that in senescence-accelerated mice a combination of resveratrol intake and habitual exercise is able to suppress the ageingassociated decline in physical performance (Murase et al. 2009). Resveratrol improves the effects of exercise in elderly rat hearts by enhancing FOXO3 phosphorylation via synergetic activation of SIRT1 and PI3K/Akt signaling (Lin et al. 2014). A similar effect was observed for curcumin supplementation. It has been documented that curcumin together with physical performance upregulates SIRT1 even more efficiently than dietary curcumin alone (Sahin et al. 2016). Curcumin supplementation affected the time of exhaustion in exercised rats. Moreover, curcumin treatment enhanced the effect of exercise and, together with exercise increased AMPK phosphorylation, NAD+/NADH ratio and SIRT1 expression in the muscle (Ray Hamidie et al. 2015). Improved exercise performance and fatigue prevention in mice was the result of increased resistance to stress conditions (Huang et al. 2015). Figure 3 summarizes the proposed mechanisms of sirtuin activation by curcumin.

Considering curcumin as a potential anti-ageing factor it is important to mention that it could act not only by mimicking of DR and exercise but is also able to inhibit the Akt/mTOR signaling pathway (Zhu et al.
2016; Guo et al. 2016; Jiao et al. 2016; Sikora et al. 2010a).

The impact of curcumin on lifespan/healthspan elongation strategies and protection from age-related pathologies is summarized in Fig. 4.

\section{Conclusions}

Numerous data presented in the literature show sirtuins as a powerful tool in anti-ageing medicine/ approach. Results from animal models, observations at the cellular level and data obtained from human studies suggest that sirtuins could be considered as a key regulator of ageing. The level of these enzymes decreases with age while their upregulation alleviates the symptoms of ageing/cellular senescence. Natural compounds present in the diet, classed as functional food/nutraceutics, could be an invaluable element of anti-ageing prophylactics or even intervention. Such compounds are nontoxic, easy to use and commonly available and could be included into a normal diet for long lasting supplementation. The huge amount of data describing curcumin activity provided convincing evidence concerning its beneficial effects. One of them could be regulation of sirtuin level/activity. However, it has to be kept in mind that all natural compounds, including curcumin, have pleiotropic activity and many molecular and cellular targets. On the other hand, the ageing process per se is multifactorial, and modulation of sirtuin level/activity, especially in such complex organism as the human being, could not be sufficient to slow it down.

Acknowledgements This study was supported by grants: National Center of Science, UMO-2011/01/B/NZ3/02137 and by the Nencki Institute statutory funds.

\section{Compliance with ethical standards}

Conflict of interest The authors declare that they have no conflict of interest.

Open Access This article is distributed under the terms of the Creative Commons Attribution 4.0 International License (http:// creativecommons.org/licenses/by/4.0/), which permits unrestricted use, distribution, and reproduction in any medium, provided you give appropriate credit to the original author(s) and the source, provide a link to the Creative Commons license, and indicate if changes were made. 


\section{References}

Abdelmohsen K, Pullmann R Jr, Lal A, Kim HH, Galban S, Yang X, Blethrow JD, Walker M, Shubert J, Gillespie DA, Furneaux H, Gorospe M (2007) Phosphorylation of HuR by Chk2 regulates SIRT1 expression. Mol Cell 25:543-557

Ahn BH, Kim HS, Song S, Lee IH, Liu J, Vassilopoulos A, Deng CX, Finkel $T$ (2008) A role for the mitochondrial deacetylase Sirt3 in regulating energy homeostasis. Proc Natl Acad Sci USA 105:14447-14452

Alcendor RR, Gao S, Zhai P, Zablocki D, Holle E, Yu X, Tian B, Wagner T, Vatner SF, Sadoshima J (2007) Sirt1 regulates aging and resistance to oxidative stress in the heart. Circ Res 100(10):1512-1521

Anwar T, Khosla S, Ramakrishna G (2016) Increased expression of SIRT2 is a novel marker of cellular senescence and is dependent on wild type p53 status. Cell Cycle 15(14):1883-1897

Arunachalam G, Samuel SM, Marei I, Ding H, Triggle CR (2014) Metformin modulates hyperglycaemia-induced endothelial senescence and apoptosis through SIRT1. Br J Pharmacol 171(2):523-535

Baell J, Walters MA (2014) Chemistry: chemical con artists foil drug discovery. Nature 513(7519):481-483

Bai B, Vanhoutte PM, Wang Y (2014) Loss-of-SIRT1 function during vascular ageing: hyperphosphorylation mediated by cyclin-dependent kinase 5. Trends Cardiovasc Med 24:81-84

Banerjee AK, Mandal A, Chanda D, Chakraborti S (2013) Oxidant, antioxidant and physical exercise. Mol Cell Biochem 253(1-2):307-312

Barber MF, Michishita-Kioi E, Xi Y, Tasselli L, Kioi M, Moqtaderi Z, Tennen RI, Paredes S, Young NL, Chen K, Struhl K, Garcia BA, Gozani O, Li W, Chua KF (2012) SIRT7 links H3K18 deacetylation to maintenance of oncogenic transformation. Nature 487(7405):114-118

Baur JA, Pearson KJ, Price NL, Jamieson HA, Lerin C, Kalra A, Prabhu VV, Allard JS, Lopez-Lluch G, Lewis K, Pistell PJ, Poosala S, Becker KG, Boss O, Gwinn D, Wang M, Ramaswamy S, Fishbein KW, Spencer RG, Lakatta EG, Le Couteur D, Shaw RJ, Navas P, Puigserver P, Ingram DK, de Cabo R, Sinclair DA (2006) Resveratrol improves health and survival of mice on a high-calorie diet. Nature 444:337-342

Bayod S, Del Valle J, Canudas AM, Lalanza JF, Sanchez-Roige S, Camins A, Escorihuela RM, Pallàs M (2011) Long-term treadmill exercise induces neuroprotective molecular changes in rat brain. J Appl Physiol 111(5):1380-1390

Bayod S, del Valle J, Lalanza JF, Sanchez-Roige S, de LuxánDelgado B, Coto-Montes A, Canudas AM, Camins A, Escorihuela RM, Pallàs M (2012) Long-term physical exercise induces changes in sirtuin 1 pathway and oxidative parameters in adult rat tissues. Exp Gerontol 47:925-935

Bell EL, Emerling BM, Ricoult SJ, Guarente L (2011) SirT3 suppresses hypoxia inducible factor 1alpha and tumor growth by inhibiting mitochondrial ROS production. Oncogene 30(26):2986-2996

Bellizzi D, Rose G, Cavalcante P, Covello G, Dato S, De Rango F, Greco V, Maggiolini M, Feraco E, Mari V, Franceschi C,
Passarino G, De Benedictis G (2005) A novel VNTR enhancer within the SIRT3 gene, a human homologue of SIR2, is associated with survival at oldest ages. Genomics 85(2):258-263

Bellizzi D, Dato S, Cavalcante P, Covello G, Di Cianni F, Passarino G, Rose G, De Benedictis G (2007) Characterization of a bidirectional promoter shared between two human genes related to aging: SIRT3 and PSMD13. Genomics 89(1):143-150

Beneke S (2012) Regulation of chromatin structure by poly(ADP-ribosyl)ation. Front Genet 3:169

Berge U, Kristensen P, Rattan SI (2008) Hormetic modulation of differentiation of normal human epidermal keratinocytes undergoing replicative senescence in vitro. Exp Gerontol 43(7):658-662

Berry A, Capone F, Giorgio M, Pelicci PG, de Kloet ER, Alleva E, Minghetti L, Cirulli F (2007) Deletion of the life span determinant p66Shc prevents age-dependent increases in emotionality and pain sensitivity in mice. Exp Gerontol 42(1-2):37-45

Bhakta-Guha D, Efferth T (2015) Hormesis: decoding two sides of the same coin. Pharmaceuticals (Basel) 8(4):865-883

Bielak-Zmijewska A, Wnuk M, Przybylska D, Grabowska W, Lewinska A, Alster O, Korwek Z, Cmoch A, Myszka A, Pikula S, Mosieniak G, Sikora E (2014) A comparison of replicative senescence and doxorubicin-induced premature senescence of vascular smooth muscle cells isolated from human aorta. Biogerontology 15(1):47-64

Boily G, Seifert EL, Bevilacqua L, He XH, Sabourin G, Estey C, Moffat C, Crawford S, Saliba S, Jardine K, Xuan J, Evans M, Harper ME, McBurney MW (2008) SirT1 regulates energy metabolism and response to caloric restriction in mice. PLoS ONE 3(3):e1759

Bonkowski MS, Sinclair DA (2016) Slowing ageing by design: the rise of NAD + and sirtuin-activating compounds. Nat Rev Mol Cell Biol 7(11):679-690

Bordone L, Guarente L (2005) Calorie restriction, SIRT1 and metabolism: understanding longevity. Nat Rev Mol Cell Biol 6(4):298-305

Bori Z, Zhao Z, Koltai E, Fatouros IG, Jamurtas AZ, Douroudos II, Terzis G, Chatzinikolaou A, Sovatzidis A, Draganidis D, Boldogh I, Radak Z (2012) The effects of aging, physical training, and a single bout of exercise on mitochondrial protein expression in human skeletal muscle. Exp Gerontol 47:417-424

Bosch-Presegué L, Vaquero A (2011) The dual role of sirtuins in cancer. Genes Cancer 2(6):648-662

Bosch-Presegué L, Raurell-Vila H, Marazuela-Duque A, KaneGoldsmith N, Valle A, Oliver J, Serrano L, Vaquero A (2011) Stabilization of Suv39H1 by SirT1 is part of oxidative stress response and ensures genome protection. Mol Cell 42(2):210-223

Bouras T, Fu M, Sauve AA, Wang F, Quong AA, Perkins ND, Hay RT, Gu W, Pestell RG (2005) SIRT1 deacetylation and repression of p300 involves lysine residues 1020/1024 within the cell cycle regulatory domain 1. J Biol Chem 280:10264-10276

Braidy N, Guillemin GJ, Mansour H, Chan-Ling T, Poljak A, Grant R (2011) Age related changes in NAD+ metabolism oxidative stress and Sirt 1 activity in wistar rats. PLoS ONE 6(4):e19194 
Braidy N, Poljak A, Grant R, Jayasena T, Mansour H (2014) Mapping NAD + metabolism in the brain of ageing Wistar rats: potential targets for influencing brain senescence. Biogerontology 15(2):177-198

Braunstein M, Rose AB, Holmes SG, Alis CD, Broach JR (1993) Transcriptional silencing in yeast is associated with reduced nucleosome acetylation. Genes Dev 7:592-604

Brown K, Xie S, Qiu X, Mohrin M, Shin J, Liu Y, Zhang D, Scadden DT, Chen D (2013) SIRT3 reverses aging-associated degeneration. Cell Rep 3(2):319-327

Brown-Borg HM, Bartke A (2012) GH and IGF1: roles in energy metabolism of long-living GH mutant mice. J Gerontol A Biol Sci Med Sci 67(6):652-660

Burnett C, Valentini S, Cabreiro F, Goss M, Somogyvári M, Piper MD, Hoddinott M, Sutphin GL, Leko V, McElwee JJ, Vazquez-Manrique RP, Orfila AM, Ackerman D, Au C, Vinti G, Riesen M, Howard K, Neri C, Bedalov A, Kaeberlein M, Soti C, Partridge L, Gems D (2011) Absence of effects of Sir2 overexpression on lifespan in C. elegans and Drosophila. Nature 477(7365):482-485

Calabrese EJ (2014) Hormesis: from mainstream to therapy. J Cell Commun Signal 8(4):289-291

Canto C, Gerhart-Hines Z, Feige JN, Lagouge M, Noriega L, Milne JC, Elliott PJ, Puigserver P, Auwerx J (2009) AMPK regulates energy expenditure by modulating NAD+ metabolism and SIRT1 activity. Nature 458:1056-1060

Cardus A, Uryga AK, Walters G, Erusalimsky JD (2013) SIRT6 protects human endothelial cells from DNA damage, telomere dysfunction, and senescence. Cardiovasc Res 97(3):571-579

Cava E, Fontana L (2013) Will calorie restriction work in humans? Aging (Albany NY) 5:507-514

Chen D, Steele AD, Lindquist S, Guarente L (2005) Increase in activity during calorie restriction requires Sirt1. Science 310(5754): 1641

Chen Y, Ping J, Zhang J, Huang JH, Xia SJ, Shen ZY (2012) Study of Icariin on raising SIRT6 activity and inhibiting NF-kB inflammation signal pathway of mouse. Gerontol Health Care 338-341

Chen HZ, Wan YZ, Liu DP (2013) Cross-talk between SIRT1 and p66Shc in vascular diseases. Trends Cardiovasc Med 23(7):237-241

Cheng HL, Mostoslavsky R, Saito S, Manis JP, Gu Y, Patel P, Bronson R, Appella E, Alt FW, Chua KF (2003) Developmental defects and p53 hyperacetylation in Sir2 homo$\log$ (SIRT1)-deficient mice. Proc Natl Acad Sci USA 100:10794-10799

Chua KF, Mostoslavsky R, Lombard DB, Pang WW, Saito S, Franco S, Kaushal D, Cheng HL, Fischer MR, Stokes N, Murphy MM, Appella E, Alt FW (2005) Mammalian SIRT1 limits replicative life span in response to chronic genotoxic stress. Cell Metab 2:67-76

Chung S, Yao H, Caito S, Hwang JW, Arunachalam G, Rahman I (2010) Regulation of SIRT1 in cellular functions: role of polyphenols. Arch Biochem Biophys 501(1):79-90

Chung JH, Manganiello V, Dyck JR (2012) Resveratrol as a calorie restriction mimetic: therapeutic implications. Trends Cell Biol 22(10):546-554

Clark SJ, Falchi M, Olsson B, Jacobson P, Cauchi S, Balkau B, Marre M, Lantieri O, Andersson JC, Jernås M, Aitman TJ, Richardson S, Sjöström L, Wong HY, Carlsson LM,
Froguel P, Walley AJ (2012) Association of sirtuin 1 (SIRT1) gene SNPs and transcript expression levels with severe obesity. Obesity (Silver Spring) 20(1):178-185

Clegg A, Young J, Iliffe S, Rikkert MO, Rockwood K (2013) Frailty in elderly people. Lancet 381:752-762

Colcombe S, Kramer AF (2003) Fitness effects on the cognitive function of older adults: a meta-analytic study. Psychol Sci 14(2): $125-130$

Colman RJ, Anderson RM, Johnson SC, Kastman EK, Kosmatka KJ, Beasley TM, Allison DB, Cruzen C, Simmons HA, Kemnitz JW, Weindruch R (2009) Caloric restriction delays disease onset and mortality in rhesus monkeys. Science 325(5937):201-204

Costford SR, Bajpeyi S, Pasarica M, Albarado DC, Thomas SC, Xie H, Church TS, Jubrias SA, Conley KE, Smith SR (2010) Skeletal muscle NAMPT is induced by exercise in humans. Am J Physiol Endocrinol Metab 298:E117-E126

Coughlan KA, Valentine RJ, Ruderman NB, Saha AK (2014) AMPK activation: a therapeutic target for type 2 diabetes? Diabetes Metab Syndr Obes 7:241-253

Csiszar A, Labinskyy N, Jimenez R, Pinto JT, Ballabh P, Losonczy G, Pearson KJ, de Cabo R, Ungvari Z (2009) Anti-oxidative and anti-inflammatory vasoprotective effects of caloric restriction in aging: role of circulating factors and SIRT1. Mech Ageing Dev 130:518-527

Daitoku H, Hatta M, Matsuzaki H, Aratani S, Ohshima T, Miyagishi M, Nakajima T, Fukamizu A (2004) Silent information regulator 2 potentiates Foxo1-mediated transcription through its deacetylase activity. Proc Natl Acad Sci USA 101:10042-10047

Demirovic D, Rattan SI (2011) Curcumin induces stress response and hormetically modulates wound healing ability of human skin fibroblasts undergoing ageing in vitro. Biogerontology 12(5):437-444

Dryden SC, Nahhas FA, Nowak JE, Goustin AS, Tainsky MA (2003) Role for human SIRT2 NAD-dependent deacetylase activity in control of mitotic exit in the cell cycle. Mol Cell Biol 23:3173-3185

Du J, Zhou Y, Su X, Yu JJ, Khan S, Jiang H, Kim J, Woo J, Kim JH, Choi BH, He B, Chen W, Zhang S, Cerione RA, Auwerx J, Hao Q, Lin H (2011) Sirt5 is a NAD-dependent protein lysine demalonylase and desuccinylase. Science 334:806-809

Escande C, Nin V, Price NL, Capellini V, Gomes AP, Barbosa MT, O'Neil L, White TA, Sinclair DA, Chini EN (2013) Flavonoid apigenin is an inhibitor of the NAD+ ase CD38: implications for cellular NAD+ metabolism, protein acetylation, and treatment of metabolic syndrome. Diabetes 62(4):1084-1093

Fahy GM, West MD, Coles LS, Harris SB (eds) (2010) The future of aging: pathways to human life extension. Springer, New York

Fan W, Luo J (2010) SIRT1 regulates UV-induced DNA repair through deacetylating XPA. Mol Cell 39:247-258

Ferrara N, Rinaldi B, Corbi G, Conti V, Stiuso P, Boccuti S, Rengo G, Rossi F, Filippelli A (2008) Exercise training promotes SIRT1 activity in aged rats. Rejuvenation Res 11(1):139-150

Ferrari CKB (2004) Functional foods, herbs and nutraceuticals: towards biochemical mechanisms of healthy aging. Biogerontology 5:275-289 
Finley LW, Carracedo A, Lee J, Souza A, Egia A, Zhang J, Teruya-Feldstein J, Moreira PI, Cardoso SM, Clish CB, Pandolfi PP, Haigis MC (2011) SIRT3 opposes reprogramming of cancer cell metabolism through HIF1alpha destabilization. Cancer Cell 19(3):416-428

Flachsbart F, Croucher PJ, Nikolaus S, Hampe J, Cordes C, Schreiber S, Nebel A (2006) Sirtuin 1 (SIRT1) sequence variation is not associated with exceptional human longevity. Exp Gerontol 41(1):98-102

Fleenor BS, Sindler AL, Marvi NK, Howell KL, Zigler ML, Yoshizawa M, Seals DR (2013) Curcumin ameliorates arterial dysfunction and oxidative stress with aging. Exp Gerontol 48:269-276

Ford E, Voit R, Liszt G, Magin C, Grummt I, Guarente L (2006) Mammalian Sir2 homolog SIRT7 is an activator of RNA polymerase I transcription. Genes Dev 20:1075-1080

Francia P, delli Gatti C, Bachschmid M, Martin-Padura I, Savoia C, Migliaccio E, Pelicci PG, Schiavoni M, Lüscher TF, Volpe M, Cosentino F (2004) Deletion of p66shc gene protects against age-related endothelial dysfunction. Circulation 110(18):2889-2895

Fry JL, Al Sayah L, Weisbrod RM, Van Roy I, Weng X, Cohen RA, Bachschmid MM, Seta F (2016) Vascular smooth muscle sirtuin-1 protects against diet-induced aortic stiffness. Hypertension 68(3):775-784

Furukawa A, Tada-Oikawa S, Kawanishi S, Oikawa S (2007) $\mathrm{H}_{2} \mathrm{O}_{2}$ accelerates cellular senescence by accumulation of acetylated p53 via decrease in the function of SIRT1 by NAD+ depletion. Cell Physiol Biochem 20:45-54

Gertler AA, Cohen HY (2013) SIRT6, a protein with many faces. Biogerontology 14:629-639

Grabowska W, Kucharewicz K, Wnuk M, Lewinska A, Suszek M, Przybylska D, Mosieniak G, Sikora E, Bielak-Zmijewska A (2015) Curcumin induces senescence of primary human cells building the vasculature in a DNA damage and ATM-independent manner. Age (Dordr) 37(1):9744

Grabowska W, Suszek M, Wnuk M, Lewinska A, Wasiak E, Sikora E, Bielak-Zmijewska A (2016) Curcumin elevates sirtuin level but does not postpone in vitro senescence of human cells building the vasculature. Oncotarget 7(15):19201-19213

Graff J, Kahn M, Samiei A, Gao J, Ota KT, Rei D, Tsai LH (2013) A dietary regimen of caloric restriction or pharmacological activation of SIRT1 to delay the onset of neurodegeneration. J Neurosci 33:8951-8960

Greathouse KL, Samuels M, DiMarco NM, Criswell DS (2005) Effects of increased dietary fat and exercise on skeletal muscle lipid peroxidation and antioxidant capacity in male rats. Eur J Nutr 44(7):429-435

Grob A, Roussel P, Wright JE, McStay B, Hernandez-Verdun D, Sirri V (2009) Involvement of SIRT7 in resumption of rDNA transcription at the exit from mitosis. J Cell Sci 122(Pt 4):489-498

Guo S, Long M, Li X, Zhu S, Zhang M, Yang Z (2016) Curcumin activates autophagy and attenuates oxidative damage in EA.hy926 cells via the Akt/mTOR pathway. Mol Med Rep 13(3):2187-2193

Haigis MC, Mostoslavsky R, Haigis KM, Fahie K, Christodoulou DC, Murphy AJ, Valenzuela DM, Yancopoulos GD, Karow M, Blander G, Wolberger C, Prolla TA, Weindruch R, Alt FW, Guarente L (2006) SIRT4 inhibits glutamate dehydrogenase and opposes the effects of calorie restriction in pancreatic beta cells. Cell 126:941-954

Haigis MC, Deng CX, Finley LWS, Kim HS, Gius D (2012) SIRT3 is a mitochondrial tumor suppressor: a scientific tale that connects aberrant cellular ROS, the Warburg effect, and carcinogenesis. Cancer Res 72(10):2468-2472

Hall JA, Dominy JE, Lee Y, Puigserver P (2013) The sirtuin family's role in aging and age-associated pathologies. J Clin Invest 123:973-979

Han MK, Song EK, Guo Y, Ou X, Mantel C, Broxmeyer HE (2008) SIRT1 regulates apoptosis and Nanog expression in mouse embryonic stem cells by controlling p53 subcellular localization. Cell Stem Cell 2:241-251

Hartford CM, Ratain MJ (2007) Rapamycin: something old, something new, sometimes borrowed and now renewed. Clin Pharmacol Ther 82(4):381-388

Hayashi T, Hirshman MF, Kurth EJ, Winder WW, Goodyear LJ (1998) Evidence for 50 AMP-activated protein kinase mediation of the effect of muscle contraction on glucose transport. Diabetes 47:1369-1373

He L, Peng X, Zhu J, Liu G, Chen X, Tang C, Liu H, Liu F, Peng Y (2015) Protective effects of curcumin on acute gentamicin-induced nephrotoxicity in rats. Can J Physiol Pharmacol 93(4):275-282

Herranz D, Munoz-Martin M, Canamero M, Mulero F, Martinez-Pastor B, Fernandez-Capetillo O, Serrano M (2010) Sirt1 improves healthy ageing and protects from metabolic syndrome-associated cancer. Nat Commun 1:1-8

Hirschey MD, Shimazu T, Goetzman E, Jing E, Schwer B, Lombard DB, Grueter CA, Harris C, Biddinger S, Ilkayeva OR, Stevens RD, Li Y, Saha AK, Ruderman NB, Bain JR, Newgard CB, Farese RV Jr, Alt FW, Kahn CR, Verdin E (2010) SIRT3 regulates mitochondrial fatty-acid oxidation by reversible enzyme deacetylation. Nature 464(7285):121-125

Ho L, Titus AS, Banerjee KK, George S, Lin W, Deota S, Saha AK, Nakamura K, Gut P, Verdin E, Kolthur-Seetharam U (2013) SIRT4 regulates ATP homeostasis and mediates a retrograde signaling via AMPK. Aging (Albany NY) 5(11):835-849

Houtkooper RH, Pirinen E, Auwerx J (2012) Sirtuins as regulators of metabolism and healthspan. Nat Rev Mol Cell Biol 13:225-238

Howitz KT, Bitterman KJ, Cohen HY, Lamming DW, Lavu S, Wood JG, Zipkin RE, Chung P, Kisielewski A, Zhang LL, Scherer B, Sinclair DA (2003) Small molecule activators of sirtuins extend Saccharomyces cerevisiae lifespan. Nature 425:191-196

Hsu CP, Zhai P, Yamamoto T, Maejima Y, Matsushima S, Hariharan N, Shao D, Takagi H, Oka S, Sadoshima J (2010) Silent information regulator 1 protects the heart from ischemia/reperfusion. Circulation 122:2170-2182

Huang J, Gan Q, Han L, Li J, Zhang H, Sun Y, Zhang Z, Tong T (2008) SIRT1 overexpression antagonizes cellular senescence with activated ERK/S6k1 signaling in human diploid fibroblasts. PLoS ONE 3(3):e1710

Huang WC, Chiu WC, Chuang HL, Tang DW, Lee ZM, Wei L, Chen FA, Huang CC (2015) Effect of curcumin supplementation on physiological fatigue and physical performance in mice. Nutrients 7(2):905-921

Huang C, Wang T, Tung Y, Lin WT (2016) W effect of exercise training on skeletal muscle SIRT1 and PGC- $1 \alpha$ expression 
levels in rats of different age. Int J Med Sci 13(4):260270

Hubbard BP, Sinclair DA (2014) Small molecule SIRT1 activators for the treatment of aging and age-related diseases. Trends Pharmacol Sci 35(3):146-154

Hwang J, Yao H, Caito S, Sundar IK, Rahman I (2013) Redox regulation of SIRT1 inflammation and cellular senescence. Free Radic Biol Med 61:95-110

Imai S, Guarente L (2014) NAD+ and sirtuins in aging and disease. Trends Cell Biol 24(8):464-471

Ingram DK, Roth GS (2015) Calorie restriction mimetics: can you have your cake and eat it, too? Ageing Res Rev 20C:46-62

Ingram DK, Zhu M, Mamczarz J, Zou S, Lane MA, Roth GS, deCabo R (2006) Calorie restriction mimetics: an emerging research field. Aging Cell 5(2):97-108

Jamal J, Mustafa MR, Wong PF (2014) Paeonol protects against premature senescence in endothelial cells by modulating Sirtuin 1 pathway. J Ethnopharmacol 154:428-436

Jayasena T, Poljak A, Smythe G, Braidy N, Münch G, Sachdev P (2013) The role of polyphenols in the modulation of sirtuins and other pathways involved in Alzheimer's disease. Ageing Res Rev 12(4):867-883

Jeong MS, Xiao C, Finley LWS, Lahusen T, Souza AL, Pierce K, Li YH, Wang X, Laurent G, German NJ, Xu X, Li C, Wang RH, Lee J, Csibi A, Cerione R, Blenis J, Clish CB, Kimmelman A, Deng CX, Haigis MC (2013) SIRT4 has tumor suppressive activity and regulates the cellular metabolic response to DNA damage by inhibiting mitochondrial glutamine metabolism. Cancer Cell 23(4):450-463

Jia N, Sun Q, Su Q, Chen G (2016) SIRT1-mediated deacetylation of PGC1a attributes to the protection of curcumin against glutamate excitotoxicity in cortical neurons. Biochem Biophys Res Commun 478(3):1376-1381

Jiang H, Khan S, Wang Y, Charron G, He B, Sebastian C, Du J, Kim R, Ge E, Mostoslavsky R, Hang HC, Hao Q, Lin H (2013) SIRT6 regulates TNF-alpha secretion through hydrolysis of long-chain fatty acyl lysine. Nature 496:110-113

Jiao D, Wang J, Lu W, Tang X, Chen J, Mou H, Chen QY (2016) Curcumin inhibited HGF-induced EMT and angiogenesis through regulating c-Met dependent $\mathrm{PI} 3 \mathrm{~K} / \mathrm{Akt} / \mathrm{mTOR}$ signaling pathways in lung cancer. Mol Ther Oncolytics 3:16018

Jing E, Emanuelli B, Hirschey MD, Boucher J, Lee KY, Lombard D, Verdin EM, Kahn CR (2011) Sirtuin-3 (Sirt3) regulates skeletal muscle metabolism and insulin signaling via altered mitochondrial oxidation and reactive oxygen species production. Proc Natl Acad Sci USA 108(35):14608-14613

Johnson SC, Rabinovitch PS, Kaeberlein M (2013) mTOR is a key modulator of ageing and age-related disease. Nature 493:338-345

Kaeberlein M, McVey M, Guarente L (1999) The SIR2/3/4 complex and SIR2 alone promote longevity in Saccharomyces cerevisiae by two different mechanisms. Genes Dev 13:2570-2580

Kaeberlein M, Kirkland KT, Fields S, Kennedy BK (2004) Sir2independent life span extension by calorie restriction in yeast. PLoS Biol 2(9):E296
Kaidi A, Weinert BT, Choudhary C, Jackson SP (2010) Human SIRT6 promotes DNA end resection through CtIP deacetylation. Science 329(5997):1348-1353

Kanfi Y, Shalman R, Peshti V, Pilosof SN, Gozlan YM, Pearson KJ, Lerrer B, Moazed D, Marine JC, de Cabo R, Cohen HY (2008) Regulation of SIRT6 protein levels by nutrient availability. FEBS Lett 582(5):543-548

Kanfi Y, Naiman S, Amir G, Peshti V, Zinman G, Nahum L, Bar-Joseph Z, Cohen HY (2012) The sirtuin SIRT6 regulates lifespan in male mice. Nature 483:218-221

Kao CL, Chen LK, Chang YL, Yung MC, Hsu CC, Chen YC, Lo WL, Chen SJ, Ku HH, Hwang SJ (2010) Resveratrol protects human endothelium from $\mathrm{H}_{2} \mathrm{O}_{2}$-induced oxidative stress and senescence via SirT1 activation. J Atheroscler Thromb 17:970-979

Kauppinen A, Suuronen T, Ojala J, Kaarniranta K, Salminen A (2013) Antagonistic crosstalk between NF-kappaB and SIRT1 in the regulation of inflammation and metabolic disorders. Cell Signal 25:1939-1948

Kenyon C, Chang J, Gensch E, Rudner A, Tabtiang R (1993) A C. elegans mutant that lives twice as long as wild type. Nature 366:461-464

Kim JK, Noh JH, Jung KH, Eun JW, Bae HJ, Kim MG, Chang YG, Shen Q, Park WS, Lee JY, Borlak J, Nam SW (2013) Sirtuin 7 oncogenic potential in human hepatocellular carcinoma and its regulation by the tumor suppressors MiR-125a-5p and MiR-125b. Hepatology 57:1055-1067

Kincaid B, Bossy-Wetzel E (2013) Forever young: SIRT3 a shield against mitochondrial meltdown, aging, and neurodegeneration. Front Aging Neurosci 5:48

Kireev RA, Vara E, Tresguerres JAF (2013) Growth hormone and melatonin prevent age-related alteration in apoptosis processes in the dentate gyrus of male rats. Biogerontology 14(4):431-442

Kitani K, Osawa T, Yokozawa T (2007) The effects of tetrahydrocurcumin and green tea polyphenol on the survival of male C57BL/6 mice. Biogerontology 8:567-573

Klar AJ, Fogel S, Macleod K (1979) MAR1-a regulator of the HMa and HMalpha Loci in Sacchromyces cerevisiae. Genetics 93(1):37-50

Kong X, Guan J, Li J, Wei J, Wang R (2016) P66Shc-SIRT1 regulation of oxidative stress protects against cardio-cerebral vascular disease. Mol Neurobiol. doi:10.1007/s12035016-0073-2

Kramer AF, Erickson KI, Colcombe SJ (2006) Exercise, cognition, and the aging brain. $J$ Appl Physiol 101(4):1237-1242

Krishnan J, Danzer C, Simka T, Ukropec J, Walter KM, Kumpf S, Mirtschink P, Ukropcova B, Gasperikova D, Pedrazzini T, Krek W (2012) Dietary obesity-associated Hif1alpha activation in adipocytes restricts fatty acid oxidation and energy expenditure via suppression of the Sirt2-NAD+ system. Genes Dev 26(3):259-270

Kumar R, Mohan N, Upadhyay AD, Singh AP, Sahu V, Dwivedi S, Dey AB, Dey S (2014a) Identification of serum sirtuins as novel noninvasive protein markers for frailty. Aging Cell 13(6):975-980

Kumar S, Vikram A, Kim YR, Jacobs SJ, Irani K (2014b) P66Shc mediates increased platelet activation and aggregation in hypercholesterolemia. Biochem Biophys Res Commun 449(4):496-501 
Lai CH, Ho TJ, Kuo WW, Day CH, Pai PY, Chung LC, Liao PH, Lin FH, Wu ET, Huang CY (2014) Exercise training enhanced SIRT1 longevity signaling replaces the IGF1 survival pathway to attenuate aging-induced rat heart apoptosis. Age (Dordr) 36(5):9706

Lalanza JF, Sanchez-Roige S, Gagliano H, Fuentes S, Bayod S, Camins A, Pallàs M, Armario A, Escorihuela RM (2012) Physiological and behavioural consequences of long-term moderate treadmill exercise. Psychoneuroendocrinology 37(11):1745-1754

Langley E, Pearson M, Faretta M, Bauer UM, Frye RA, Minucci S, Pelicci PG, Kouzarides T (2002) Human SIR2 deacetylates p53 and antagonizes PML/p53-induced cellular senescence. EMBO J 21(10):2383-2396

Lee MK, Choi YJ, Sung SH, Shin DI, Kim JW, Kim YC (1995) Antihepatotoxic activity of icariin, a major constituent of Epimedium koreanum. Planta Med 61:523-526

Lee YA, Cho EJ, Yokozawa T (2008) Protective effect of persimmon (Diospyros kaki) peel proanthocyanidin against oxidative damage under $\mathrm{H}_{2} \mathrm{O}_{2}$-induced cellular senescence. Biol Pharm Bull 31:1265-1269

Lee SM, Dho SH, Ju SK, Maeng JS, Kim JY, Kwon KS (2012) Cytosolic malate dehydrogenase regulates senescence in human fibroblasts. Biogerontology 13(5):525-536

Lescai F, Blanche H, Nebel A, Beekman M, Sahbatou M, Flachsbart F, Slagboom E, Schreiber S, Sorbi S, Passarino G, Franceschi C (2009) Human longevity and 11p15.5: a study in 1321 centenarians. Eur J Hum Genet 17(11):1515-1519

Lewinska A, Wnuk M, Grabowska W, Zabek T, Semik E, Sikora E, Bielak-Żmijewska A (2015) Curcumin induces oxidation-dependent cell cycle arrest mediated by SIRT7 inhibition of rDNA transcription in human aortic smooth muscle cells. Toxicol Lett 233(3):227-238

Li W, Zhang B, Tang J, Cao Q, Wu Y, Wu C, Guo J, Ling EA, Liang F (2007) Sirtuin 2, a mammalian homolog of yeast silent information regulator-2 longevity regulator, is an oligodendroglial protein that deacetylates cell differentiation through deacetylating alpha-tubulin. J Neurosci 27:2602-2616

Li K, Casta A, Wang R, Lozada E, Fan W, Kane S, Ge Q, Gu W, Orren D, Luo J (2008) Regulation of WRN protein cellular localization and enzymatic activities by SIRT1-mediated deacetylation. J Biol Chem 283:7590-7598

Li S, Banck M, Mujtaba S, Zhou MM, Sugrue MM, Walsh MJ (2010) p53-induced growth arrest is regulated by the mitochondrial SirT3 deacetylase. PLoS ONE 5:e10486

Li J, Chen LJ, Hu SS, Wang YF (2014) Effect of dogwood polysaccharide on the expression of Sirt1 gene in eye lens of the aging rats. Evaluation and Analysis of Drug-Use in Hospitals of China. pp 875-878

Liao VH, Yu CW, Chu YJ, Li WH, Hsieh YC, Wang TT (2011) Curcumin-mediated lifespan extension in Caenorhabditis elegans. Mech Ageing Dev 132(10):480-487

Lin SJ, Defossez PA, Guarente L (2000) Requirement of NAD and SIR2 for life-span extension by calorie restriction in Saccharomyces cerevisiae. Science 289(5487):2126-2128

Lin ZF, Xu HB, Wang JY, Lin Q, Ruan Z, Liu FB, Jin W, Huang HH, Chen X (2013) SIRT5 desuccinylates and activates SOD1 to eliminate ROS. Biochem Biophys Res Commun 441(1):191-195
Lin CH, Lin CC, Ting WJ, Pai PY, Kuo CH, Ho TJ, Kuo WW, Chang CH, Huang CY, Lin WT (2014) Resveratrol enhanced FOXO3 phosphorylation via synergetic activation of SIRT1 and PI3K/Akt signaling to improve the effects of exercise in elderly rat hearts. Age (Dordr) 36(5):9705

Liu Z, Gan L, Liu G, Chen Y, Wu T, Feng F, Sun C (2016) Sirt1 decreased adipose inflammation by interacting with Akt2 and inhibiting mTOR/S6K1 pathway in mice. J Lipid Res 57(8):1373-1381

Longo VD, Antebi A, Bartke A, Barzilai N, Brown-Borg HM, Caruso C, Curiel TJ, de Cabo R, Franceschi C, Gems D, Ingram DK, Johnson TE, Kennedy BK, Kenyon C, Klein S, Kopchick JJ, Lepperdinger G, Madeo F, Mirisola MG, Mitchell JR, Passarino G, Rudolph KL, Sedivy JM, Shadel GS, Sinclair DA, Spindler SR, Suh Y, Vijg J, Vinciguerra M, Fontana L (2015) Interventions to slow aging in humans: are we ready? Aging Cell 14(4):497-510

Ma L, Wang G, Chen Z, Li Z, Yao J, Zhao H, Wang S, Ma Z, Chang H, Tian X (2014) Modulating the p66shc signaling pathway with protocatechuic acid protects the intestine from ischemiareperfusion injury and alleviates secondary liver damage. Sci World J 2014:387640

Mao Z, Tian X, Van Meter M, Ke Z, Gorbunova V, Seluanov A (2011) Sirtuin 6 (SIRT6) rescues the decline of homologous recombination repair during replicative senescence. Proc Natl Acad Sci USA 109(29):11800-11805

Martins R, Lithgow GJ, Link W (2016) Long live FOXO: unraveling the role of FOXO proteins in aging and longevity. Aging Cell 15(2):196-207

Marton O, Koltai E, Nyakas C, Bakonyi T, Zenteno-Savin T, Kumagai S, Goto S, Radak Z (2010) Aging and exercise affect the level of protein acetylation and SIRT1 activity in cerebellum of male rats. Biogerontology 11:679-686

Masoro EJ (2005) Overview of caloric restriction and ageing. Mech Ageing Dev 126(9):913-922

Matsuzaki H, Daitoku H, Hatta M, Aoyama H, Yoshimochi K, Fukamizu A (2005) Acetylation of Foxo1 alters its DNAbinding ability and sensitivity to phosphorylation. Proc Natl Acad Sci USA 102:11278-11283

McBurney MW, Yang X, Jardine K, Hixon M, Boekelheide K, Webb JR, Lansdorp PM, Lemieux M (2003) The mammalian SIR $2 \alpha$ protein has a role in embryogenesis and gametogenesis. Mol Cell Biol 23:38-54

McCarter RJ, Shimokawa I, Ikeno Y, Higami Y, Hubbard GB, Yu BP, McMahan CA (1997) Physical activity as a factor in the action of dietary restriction on aging: effects in Fischer 344 rats. Aging (Milano) 9:73-79

McLure KG, Takagi M, Kastan MB (2004) NAD+ modulates p53 DNA binding specificity and function. Mol Cell Biol 24:9958-9967

Melendez A, Talloczy Z, Seaman M, Eskelinen EL, Hall DH, Levine B (2003) Autophagy genes are essential for dauer development and life-span extension in C. elegans. Science 301:1387-1391

Mercken EM, Mitchell SJ, Martin-Montalvo A, Minor RK, Almeida M, Gomes AP, Scheibye-Knudsen M, Palacios HH, Licata JJ, Zhang Y, Becker KG, Khraiwesh H, González-Reyes JA, Villalba JM, Baur JA, Elliott P, Westphal C, Vlasuk GP, Ellis JL, Sinclair DA, Bernier M, de Cabo R (2014) SRT2104 extends survival of male mice on a 
standard diet and preserves bone and muscle mass. Aging Cell 13(5):787-796

Michan S, Sinclair D (2007) Sirtuins in mammals: insights into their biological function. Biochem J 404:1-13

Michishita E, McCord RA, Berber E, Kioi M, Padilla-Nash H, Damian M, Cheung P, Kusumoto R, Kawahara TL, Barrett JC, Chang HY, Bohr VA, Ried T, Gozani O, Chua KF (2008) SIRT6 is a histone H3 lysine 9 deacetylase that modulates telomeric chromatin. Nature 452(7186):492-496

Milman S, Atzmon G, Huffman DM, Wan J, Crandall JP, Cohen P, Barzilai N (2014) Low insulin-like growth factor-1 level predicts survival in humans with exceptional longevity. Aging Cell 13:769-771

Minor RK, Baur JA, Gomes AP, Ward TM, Csiszar A, Mercken EM, Abdelmohsen K, Shin YK, Canto C, ScheibyeKnudsen M, Krawczyk M, Irusta PM, MartinMontalvo A, Hubbard BP, Zhang Y, Lehrmann E, White AA, Price NL, Swindell WR, Pearson KJ, Becker KG, Bohr VA, Gorospe M, Egan JM, Talan MI, Auwerx J, Westphal CH, Ellis JL, Ungvari Z, Vlasuk GP, Elliott PJ, Sinclair DA, de Cabo R (2011) SRT1720 improves survival and healthspan of obese mice. Sci Rep 1:70

Mirochnic S, Wolf S, Staufenbiel M, Kempermann G (2009) Age effects on the regulation of adult hippocampal neurogenesis by physical activity and environmental enrichment in the APP23 mouse model of Alzheimer disease. Hippocampus 19(10):1008-1018

Miyazawa M, Tsuji Y (2014) Evidence for a novel antioxidant function and isoform-specific regulation of the human p66Shc gene. Mol Biol Cell 25(13):2116-2127

Morris BJ (2013) Seven sirtuins for seven deadly diseases of aging. Free Radic Biol Med 56:133-171

Mosieniak G, Adamowicz M, Alster O, Jaskowiak H, Szczepankiewicz AA, Wilczynski GM, Ciechomska IA, Sikora E (2012) Curcumin induces permanent growth arrest of human colon cancer cells: link between senescence and autophagy. Mech Ageing Dev 133(6):444-455

Mosieniak G, Sliwinska MA, Przybylska D, Grabowska W, Sunderland P, Bielak-Zmijewska A, Sikora E (2016) Curcumin-treated cancer cells show mitotic disturbances leading to growth arrest and induction of senescence phenotype. Int J Biochem Cell Biol 74:33-43

Mostoslavsky R, Chua KF, Lombard DB, Pang WW, Fischer MR, Gellon L, Liu P, Mostoslavsky G, Franco S, Murphy MM, Mills KD, Patel P, Hsu JT, Hong AL, Ford E, Cheng HL, Kennedy C, Nunez N, Bronson R, Frendewey D, Auerbach W, Valenzuela D, Karow M, Hottiger MO, Hursting S, Barrett JC, Guarente L, Mulligan R, Demple B, Yancopoulos GD, Alt FW (2006) Genomic instability and aging-like phenotype in the absence of mammalian SIRT6. Cell 124(2):315-329

Mouchiroud L, Molin L, Dalliere N, Solari F (2010) Life span extension by resveratrol, rapamycin and metformin: the promise of dietary restriction mimetics for an healthy aging. BioFactors 36:377-382

Murase T, Haramizu S, Ota N, Hase T (2009) Suppression of the aging-associated decline in physical performance by a combination of resveratrol intake and habitual exercise in senescence-accelerated mice. Biogerontology 10:423-434
Murayama A, Ohmori K, Fujimura A, Ohmori K, Fujimura A, Minami H, Yasuzawa-Tanaka K, Kuroda T, Oie S, Daitoku H, Okuwaki M, Nagata K, Fukamizu A, Kimura K, Shimizu T, Yanagisawa J (2008) Epigenetic control of rDNA loci in response to intracellular energy status. Cell 133:627-639

Muth V, Nadaud S, Grummt I, Voit R (2001) Acetylation of TAF(I)68, a subunit of TIF-IB/SL1, activates RNA polymerase I transcription. EMBO J 20:1353-1362

Nakagawa T, Guarente L (2011) Sirtuins at a glance. J Cell Sci 124:833-838

Oberdoerffer P, Michan S, McVay M, Mostoslavsky R, Vann J, Park SK, Hartlerode A, Stegmuller J, Hafner A, Loerch P, Wright SM, Mills KD, Bonni A, Yankner BA, Scully R, Prolla TA, Alt FW, Sinclair DA (2008) SIRT1 redistribution on chromatin promotes genomic stability but alters gene expression during aging. Cell 135(5):907-918

Olszanecki R, Jawień J, Gajda M, Mateuszuk L, Gebska A, Korabiowska M, Chłopicki S, Korbut R (2005) Effect of curcumin on atherosclerosis in apoE/LDLR-double knockout mice. J Physiol Pharmacol 56(4):627-635

Ota H, Eto M, Kano MR, Ogawa S, Iijima K, Akishita M, Ouchi Y (2008) Cilostazol inhibits oxidative stress-induced premature senescence via upregulation of Sirt1 in human endothelial cells. Arterioscler Thromb Vasc Biol 28:1634-1639

Ota H, Eto M, Kano MR, Kahyo T, Setou M, Ogawa S, Iijima K, Akishita M, Ouchi Y (2010) Induction of endothelial nitric oxide synthase, SIRT1, and catalase by statins inhibits endothelial senescence through the Akt pathway. Arterioscler Thromb Vasc Biol 30:2205-2211

Palacios JA, Herranz D, De Bonis ML, Velasco S, Serrano M, Blasco MA (2010) SIRT1 contributes to telomere maintenance and augments global homologous recombination. J Cell Biol 191(7):1299-1313

Park S, Seong R, Kim J, Son S, Kim Y, Yokozawa T, Shin OS (2016) Oligonol promotes anti-aging pathways via modulation of SIRT1-AMPK-autophagy pathway. Nutr Res Pract 10(1):3-10

Pasini E, Le Douairon Lahaye S, Flati V, Assanelli D, Corsetti G, Speca S, Bernabei R, Calvani R, Marzetti E (2012) Effects of treadmill exercise and training frequency on anabolic signaling pathways in the skeletal muscle of aged rats. Exp Gerontol 47(1):23-28

Poulose N, Raju R (2015) Sirtuin regulation in aging and injury. Biochim Biophys Acta 1852:2442-2455

Queen BL, Tollefsbol TO (2010) Polyphenols and aging. Curr Aging Sci 3(1):34-42

Radak Z, Chung HY, Goto S (2008) Systemic adaptation to oxidative challenge induced by regular exercise. Free Radic Biol Med 44:153-159

Ramis MR, Esteban S, Miralles A, Tan DX, Reiter RJ (2015) Caloric restriction, resveratrol and melatonin: role of SIRT1 and implications for aging and related-diseases. Mech Ageing Dev 146-148:28-41

Rattan SI (2012) Rationale and methods of discovering hormetins as drugs for healthy ageing. Expert Opin Drug Discov 7(5):439-448

Ray Hamidie RD, Yamada T, Ishizawa R, Saito Y, Masuda K (2015) Curcumin treatment enhances the effect of exercise 
on mitochondrial biogenesis in skeletal muscle by increasing cAMP levels. Metabolism 64(10):1334-1347

Rogina B, Helfand SL (2004) Sir2 mediates longevity in the fly through a pathway related to calorie restriction. Proc Natl Acad Sci USA 101(45):15998-16003

Rolland T, Abellan van Kan G, Vellas B (2010) Healthy brain aging: role of exercise and physical activity. Clin Geriatr Med 26(1):75-78

Rose G, Dato S, Altomare K, Bellizzi D, Garasto S, Greco V, Passarino G, Feraco E, Mari V, Barbi C, BonaFe M, Franceschi C, Tan Q, Boiko S, Yashin AI, De Benedictis G (2003) Variability of the SIRT3 gene, human silent information regulator Sir2 homologue, and survivorship in the elderly. Exp Gerontol 38(10):1065-1070

Ruderman NB, Xu XJ, Nelson L, Cacicedo JM, Saha AK, Lan F, Ido Y (2010) AMPK and SIRT1: a long-standing partnership? Am J Physiol Endocrinol Metab 298(4):E751-E760

Sahin K, Pala R, Tuzcu M, Ozdemir O, Orhan C, Sahin N, Juturu V (2016) Curcumin prevents muscle damage by regulating $\mathrm{NF}-\kappa \mathrm{B}$ and Nrf2 pathways and improves performance: an in vivo model. J Inflamm Res 9:147-154

Salminen A, Kaarniranta K (2012) AMP-activated protein kinase (AMPK) controls the aging process via an integrated signaling network. Ageing Res Rev 11(2):230-241

Salvioli S, Sikora E, Cooper EL, Franceschi C (2007) Curcumin in cell death processes: a challenge for CAM of age-related pathologies. Evid Based Complement Altern Med 4(2):181-190

Sandur SK, Ichikawa H, Pandey MK, Kunnumakkara AB, Sung B, Sethi G, Aggarwal BB (2007) Role of pro-oxidants and antioxidants in the anti-inflammatory and apoptotic effects of curcumin (diferuloylmethane). Free Radic Biol Med 43:568-580

Sasaki T, Maier B, Bartke A, Scrable H (2006) Progressive loss of SIRT1 with cell cycle withdrawal. Aging Cell 5:413-422

Satoh A, Brace CS, Rensing N, Cliften P, Wozniak DF, Herzog ED, Yamada KA, Imai S (2013) Sirt1 extends life span and delays aging in mice through the regulation of $\mathrm{Nk} 2$ homeobox 1 in the DMH and LH. Cell Metab 18:416-430

Sauve AA, Moir RD, Schramm VL, Willis IM (2005) Chemical activation of Sir2-dependent silencing by relief of nicotinamide inhibition. Mol Cell 17(4):595-601

Schafer MJ, White TA, Evans G, Tonne JM, Verzosa GC, Stout MB, Mazula DL, Palmer AK, Baker DJ, Jensen MD, Torbenson MS, Miller JD, Ikeda Y, Tchkonia T, van Deursen JM, Kirkland JL, LeBrasseur NK (2016) Exercise prevents diet-induced cellular senescence in adipose tissue. Diabetes 65(6):1606-1615

Scher MB, Vaquero A, Reinberg D (2007) SirT3 is a nuclear NAD+-dependent histone deacetylase that translocates to the mitochondria upon cellular stress. Genes Dev 21:920-928

Schwer B, North BJ, Frye RA, Ott M, Verdin E (2002) The human silent information regulator (Sir)2 homologue hSIRT3 is a mitochondrial nicotinamide adenine dinucleotide-dependent deacetylase. J Cell Biol 158:647-657

Sedelnikova OA, Horikawa I, Zimonjic DB, Popescu NC, Bonner WM, Barrett JC (2004) Senescing human cells and ageing mice accumulate DNA lesions with unrepairable doublestrand breaks. Nat Cell Biol 6:168-170
Sharma A, Diecke S, Zhang WY, Lan F, He C, Mordwinkin NM, Chua KF, Wu JC (2013) The role of SIRT6 protein in aging and reprogramming of human induced pluripotent stem cells. J Biol Chem 288:18439-18447

Shimazu T, Hirschey MD, Hua L, Dittenhafer-Reed KE, Schwer B, Lombard DB, Li Y, Bunkenborg J, Alt FW, Denu JM, Jacobson MP, Verdin E (2010) SIRT3 deacetylates mitochondrial 3-hydroxy-3-methylglutaryl CoA synthase 2 and regulates ketone body production. Cell Metab 12(6):654-661

Sikora E, Bielak-Zmijewska A, Mosieniak G, Piwocka K (2010a) The promise of slow down ageing may come from curcumin. Curr Pharm Des 16(7):884-892

Sikora E, Scapagnini G, Barbagallo M (2010b) Curcumin, inflammation, ageing and age-related diseases. Immun Ageing 7(1): 1

Sinclair D, Guarente L (1997) Extrachromosomal rDNA circles-a cause of aging in yeast. Cell 91:1033-1042

Slentz CA, Bateman LA, Willis LH, Shields AT, Tanner CJ, Piner LW, Hawk VH, Muehlbauer MJ, Samsa GP, Nelson RC, Huffman KM, Bales CW, Houmard JA, Kraus WE (2011) Effects of aerobic vs. resistance training on visceral and liver fat stores, liver enzymes, and insulin resistance by HOMA in overweight adults from STRRIDE AT/RT. Am J Physiol Endocrinol Metab 301(5):E1033-E1039

Song XM, Fiedler M, Galuska D, Ryder JW, Fernstrom M, Chibalin AV, Wallberg-Henriksson H, Zierath JR (2002) 5-Aminoimidazole-4-carboxamide ribonucleoside treatment improves glucose homeostasis in insulin-resistant diabetic (ob/ob) mice. Diabetologia 45:56-65

Srivastava G, Mehta JL (2009) Currying the heart: curcumin and cardioprotection. J Cardiovasc Pharmacol Ther 14(1):22-27

Suh Y, Atzmon G, Cho MO, Hwang D, Liu B, Leahy DJ, Barzilai N, Cohen P (2008) Functionally significant insulin-like growth factor I receptor mutations in centenarians. Proc Natl Acad Sci USA 105:3438-3442

Sun Q, Jia N, Wang W, Jin H, Xu J, Hu H (2014) Activation of SIRT1 by curcumin blocks the neurotoxicity of amyloidbeta25-35 in rat cortical neurons. Biochem Biophys Res Commun 448:89-94

Sun Y, Hu X, Hu G, Xu C, Jiang H (2015) Curcumin attenuates hydrogen peroxide-induced premature senescence via the activation of SIRT1 in human umbilical vein endothelial cells. Biol Pharm Bull 38(8):1134-1141

Suo R, Zhao ZZ, Tang ZH, Ren Z, Liu X, Liu LS, Wang Z, Tang CK, Wei DH, Jiang ZS (2013) Hydrogen sulfide prevents $\mathrm{H}_{2} \mathrm{O}_{2}$-induced senescence in human umbilical vein endothelial cells through SIRT1 activation. Mol Med Rep 7:1865-1870

Tanner KG, Landty J, Sternglanz R, Denu JM (2000) Silent information regulator 2 family of NAD-dependent histone/ protein deacetylases generates a unique product, 1-Oacetyl-ADP-ribose. Proc Natl Acad Sci USA 97:14178-14182

Tatone C, Di Emidio G, Vitti M, Di Carlo M, Santini S Jr, D'Alessandro AM, Falone S, Amicarelli F (2015) Sirtuin functions in female fertility: possible role in oxidative stress and aging. Oxid Med Cell Longev 2015:659687

Tennen RI, Chua KF (2011) Chromatin regulation and genome maintenance by mammalian SIRT6. Trends Biochem Sci $36: 39-46$ 
Tissenbaum HA, Guarente L (2001) Increased dosage of a sir-2 gene extends lifespan in Caenorhabditis elegans. Nature 410(6825):227-230

Tran D, Bergholz J, Zhang H, He H, Wang Y, Zhang Y, Li Q, Kirkland JL, Xiao ZX (2014) Insulin-like growth factor-1 regulates the SIRT1-p53 pathway in cellular senescence. Aging Cell 13:669-678

Tsang AW, Escalante-Semerena JC (1998) CobB, a new member of the SIR2 family of eucaryotic regulatory proteins, is required to compensate for the lack of nicotinate mononucleotide:5,6-dimethylbenzimidazole phosphoribosyltransferase activity in cobT mutants during cobalamin biosynthesis in Salmonella typhimurium LT2. J Biol Chem 273(48):31788-31794

Tsuchiya M, Dang N, Kerr EO, Hu D, Steffen KK, Oakes JA, Kennedy BK, Kaeberlein M (2006) Sirtuin-independent effects of nicotinamide on lifespan extension from calorie restriction in yeast. Aging Cell 5:505-514

Ugur S, Ulu R, Dogukan A, Gurel A, Yigit IP, Gozel N, Aygen $B$, Ilhan N (2015) The renoprotective effect of curcumin in cisplatin-induced nephrotoxicity. Ren Fail 37(2):332-336

Vakhrusheva O, Smolka C, Gajawada P, Kostin S, Boettger T, Kubin T, Braun T, Bober E (2008) Sirt7 increases stress resistance of cardiomyocytes and prevents apoptosis and inflammatory cardiomyopathy in mice. Circ Res 102(6):703-710

van Praag H (2009) Exercise and the brain: something to chew on. Trends Neurosci 32(5):283-290

Vaquero A (2009) The conserved role of sirtuins in chromatin regulation. Int J Dev Biol 53:303-322

Vaquero A, Scher MB, Lee DH, Sutton A, Cheng HL, Alt FW, Serrano L, Sternglanz R, Reinberg D (2006) SirT2 is a histone deacetylase with preference for histone H4 Lys 16 during mitosis. Genes Dev 20:1256-1261

Vaquero A, Scher M, Erdjument-Bromage H, Tempst P, Serrano L, Reinberg D (2007) SIRT1 regulates the histone methyltransferase SUV39H1 during heterochromatin formation. Nature 450(7168):440-444

Vassallo PF, Simoncini S, Ligi I, Chateau AL, Bachelier R, Robert S, Morere J, Fernandez S, Guillet B, Marcelli M, Tellier E, Pascal A, Simeoni U, Anfosso F, Magdinier F, Dignat-George F, Sabatier F (2014) Accelerated senescence of cord blood endothelial progenitor cells in premature neonates is driven by SIRT1 decreased expression. Blood 123(13):2116-2126

Vikram A, Kim YR, Kumar S, Naqvi A, Hoffman TA, Kumar A, Miller FJ Jr, Kim CS, Irani K (2014) Canonical Wnt signaling induces vascular endothelial dysfunction via p66Shc-regulated reactive oxygen species. Arterioscler Thromb Vasc Biol 34(10):2301-2309

Wang F, Nguyen M, Qin FX, Tong Q (2007) SIRT2 deacetylates FOXO3a in response to oxidative stress and caloric restriction. Aging Cell 6:505-514

Wang RH, Sengupta K, Li C, Li C, Kim HS, Cao L, Xiao C, Kim S, Xu X, Zheng Y, Chilton B, Jia R, Zheng ZM, Appella E, Wang XW, Ried T, Deng CX (2008) Impaired DNA damage response, genome instability, and tumorigenesis in SIRT1 mutant mice. Cancer Cell 14:312-323

Wang P, Xu TY, Guan YF, Tian WW, Viollet B, Rui YC, Zhai QW, Su DF, Miao CY (2011) Nicotinamide phosphoribosyltransferase protects against ischemic stroke through
SIRT1-dependent adenosine monophosphate-activated kinase pathway. Ann Neurol 69:360-374

Wang G, Han T, Nijhawan D, Theodoropoulos P, Naidoo J, Yadavalli S, Mirzaei H, Pieper AA, Ready JM, McKnight SL (2014) P7C3 neuroprotective chemicals function by activating the rate-limiting enzyme in NAD salvage. Cell 158:1324-1334

Wang Y, Liang X, Chen Y, Zhao X (2016) Screening SIRT1 activators from medicinal plants as bioactive compounds against oxidative damage in mitochondrial function. Oxid Med Cell Longev 2016:4206392

Watroba M, Szukiewicz D (2016) The role of sirtuins in aging and age-related diseases. Adv Med Sci 61:52-62

Weed JL, Lane MA, Roth GS, Speer DL, Ingram DK (1997) Activity measures in rhesus monkeys on long-term calorie restriction. Physiol Behav 62:97-103

Weindruch R (1996) The retardation of aging by caloric restriction: studies in rodents and primates. Toxicol Pathol 24(6):742-745

Xia W, Geng K (2016) A sirtuin activator and an anti-inflammatory molecule-multifaceted roles of adjudin and its potential applications for aging-related diseases. Semin Cell Dev Biol 59:71-78

Xiao C, Kim HS, Lahusen T, Wang RH, Xu X, Gavrilova O, Jou W, Gius D, Deng CX (2010) SIRT6 deficiency results in severe hypoglycemia by enhancing both basal and insulinstimulated glucose uptake in mice. J Biol Chem 285(47):36776-36784

Xiong S, Salazar G, Patrushev N, Alexander RW (2011) FoxO1 mediates an auto-feedback loop regulating SIRT1 expression. J Biol Chem 286:5289-5299

Yang T, Sauve AA (2006) NAD metabolism and sirtuins: metabolic regulation of protein deacetylation in stress and toxicity. AAPS J 8:E632-E643

Yang X, Thomas DP, Zhang X, Culver BW, Alexander BM, Murdoch WJ, Rao MN, Tulis DA, Ren J, Sreejayan N (2006) Curcumin inhibits platelet-derived growth factorstimulated vascular smooth muscle cell function and injury-induced neointima formation. Arterioscler Thromb Vasc Biol 26(1):85-90

Yang Y, Duan W, Lin Y, Yi W, Liang Z, Yan J, Wang N, Deng C, Zhang S, Li Y, Chen W, Yu S, Yi D, Jin Z (2013) SIRT1 activation by curcumin pretreatment attenuates mitochondrial oxidative damage induced by myocardial ischemia reperfusion injury. Free Radic Biol Med 65:667-679

Yang N, Song T, Chang Y, Chen M, Hu M (2015) Up-regulation of nicotinamide phosphoribosyltransferase and increase of $\mathrm{NAD}+$ levels by glucose restriction extend replicative lifespan of human fibroblast Hs68 cells. Biogerontology 16(1):31-42

Yuan Z, Zhang X, Sengupta N, Lane WS, Seto E (2007) SIRT1 regulates the function of the Nijmegen breakage syndrome protein. Mol Cell 27:149-162

Zhang J (2003) Are poly(ADP-rybosyl)ation by PARP-1 and deacetylation by Sir2 linked? BioEssays 25:808-814

Zhang T, Zhou Y, Li L, Wang H, Ma X, Qian W, Shen W, Schatten H, Sun Q (2016a) SIRT1, 2, 3 protect mouse oocytes from postovulatory aging. Aging 8(4):685-696

Zhang N, Li Z, Mu W, Li L, Liang Y, Lu M, Wang Z, Qiu Y, Wang Z (2016b) Calorie restriction-induced SIRT6 
activation delays aging by suppressing NF- $\kappa \mathrm{B}$ signaling. Shock 45(4):411-418

Zhao Y, Yang J, Liao W, Liu X, Zhang H, Wang S, Wang D, Feng J, Yu L, Zhu WG (2010) Cytosolic FoxO1 is essential for the induction of autophagy and tumour suppressor activity. Nat Cell Biol 12:665-675

Zhao YN, Li WF, Li F, Zhang Z, Dai YD, Xu AL, Qi C, Gao JM, Gao J (2013) Resveratrol improves learning and memory in normally aged mice through microRNA-CREB pathway. Biochem Biophys Res Commun 435:597-602

Zheng M, Qiao W, Cui J, Liu L, Liu H, Wang Z, Yan C (2014) Hydrogen sulfide delays nicotinamide-induced premature senescence via upregulation of SIRT1 in human umbilical vein endothelial cells. Mol Cell Biochem 393:59-67

Zhong L, D'Urso A, Toiber D, Sebastian C, Henry RE, Vadysirisack DD, Guimaraes A, Marinelli B, Wikstrom
JD, Nir T, Clish CB, Vaitheesvaran B, Iliopoulos O, Kurland I, Dor Y, Weissleder R, Shirihai OS, Ellisen LW, Espinosa JM, Mostoslavsky R (2010) The histone deacetylase Sirt6 regulates glucose homeostasis via Hif1alpha. Cell 140(2):280-293

Zhou S, Chen HZ, Wan YZ, Zhang QJ, Wei YS, Huang S, Liu JJ, Lu YB, Zhang ZQ, Yang RF, Zhang R, Cai H, Liu DP, Liang CC (2011) Repression of P66Shc expression by SIRT1 contributes to the prevention of hyperglycemia-induced endothelial dysfunction. Circ Res 109(6):639-648

Zhu FQ, Chen MJ, Zhu M, Zhao RS, Qiu W, Xu X, Liu H, Zhao HW, Yu RJ, Wu XF, Zhang K, Huang H (2016) Curcumin suppresses epithelial-mesenchymal transition of renal tubular epithelial cells through the inhibition of Akt/mTOR pathway. Biol Pharm Bull 40(1):17-24 